\title{
MASER AND INFRARED STUDIES OF OXYGEN-RICH LATE/POST-ASYMPTOTIC GIANT BRANCH STARS AND WATER FOUNTAINS: DEVELOPMENT OF A NEW IDENTIFICATION METHOD
}

\author{
Bosco H. K. YunG ${ }^{1}$, Jun-ICHi NAKAshima ${ }^{1,2}$, And Christian Henkel ${ }^{3,4}$ \\ ${ }^{1}$ Department of Physics, The University of Hong Kong, Pokfulam Road, Hong Kong, China \\ ${ }^{2}$ Ural Federal University, Lenin Avenue, 51, Ekaterinburg 620000, Russia \\ ${ }^{3}$ Max-Planck-Institut für Radioastronomie, Auf dem Hügel 69, D-53121 Bonn, Germany \\ ${ }^{4}$ Astronomy Department, King Abdulaziz University, P.O. Box 80203, Jeddah 21589, Saudi Arabia \\ Received 2014 June 2; accepted 2014 August 17; published 2014 September 25
}

\begin{abstract}
We explored an efficient method to identify evolved stars with oxygen-rich envelopes in the late asymptotic giant branch (AGB) or post-AGB phase of stellar evolution, which include a rare class of objects-the "water fountains (WF)." Our method considers the $\mathrm{OH}$ and $\mathrm{H}_{2} \mathrm{O}$ maser spectra, the near-infrared $Q$-parameters (these are color indices accounting for the effect of extinction), and far-infrared AKARI colors. Here we first present the results of a new survey on $\mathrm{OH}$ and $\mathrm{H}_{2} \mathrm{O}$ masers. There were 108 color-selected objects: 53 of them were observed in the three $\mathrm{OH}$ maser lines $(1612,1665$, and $1667 \mathrm{MHz}$ ), with 24 detections (16 new for $1612 \mathrm{MHz}$ ); and 106 of them were observed in the $\mathrm{H}_{2} \mathrm{O}$ maser line $(22 \mathrm{GHz}$ ), with 24 detections (12 new). We identify a new potential WF source, IRAS 19356+0754, with large velocity coverages of both $\mathrm{OH}$ and $\mathrm{H}_{2} \mathrm{O}$ maser emission. In addition, several objects with high-velocity $\mathrm{OH}$ maser emission are reported for the first time. The $Q$-parameters as well as the infrared [09]-[18] and [18]-[65] AKARI colors of the surveyed objects are then calculated. We suggest that these infrared properties are effective in isolating aspherical from spherical objects, but the morphology may not necessarily be related to the evolutionary status. Nonetheless, by considering altogether the maser and infrared properties, the efficiency of identifying oxygen-rich late/post-AGB stars could be improved.
\end{abstract}

Key words: infrared: stars - masers - stars: AGB and post-AGB - stars: evolution - stars: winds, outflows

Online-only material: color figures

\section{INTRODUCTION}

The post-asymptotic giant branch (post-AGB) phase is a short transition phase for intermediate-mass stars (about 1-8 $M_{\odot}$ ) in the course of stellar evolution. It comes after the masslosing AGB phase that creates thick circumstellar envelopes, and before the planetary nebula $(\mathrm{PN})$ phase in which those envelopes are ionized by radiation from exposed hot central stars and interstellar ultraviolet emission (see Van Winckel 2003, for a review). The duration of the post-AGB phase could be just $\sim 30 \mathrm{yr}$ in the case of a relatively massive star (i.e., close to $8 M_{\odot}$ ), or up to $\sim 5 \times 10^{4} \mathrm{yr}$ for a lower mass star (Blöcker 1995). Post-AGB stars are often invisible in the optical wavelength range due to their low envelope temperature $(\leqslant 200 \mathrm{~K})$. They are usually observable at longer wavelengths because radiation from the stellar photosphere is absorbed and re-emitted by the thick envelope. As opposed to usual AGB stars, most of the postAGB stars are surrounded by circumstellar shells with aspherical morphology, showing bipolar or even multipolar structures in high-resolution infrared images (e.g., Lagadec et al. 2011). Sahai \& Trauger (1998) suggested that high-velocity jets will form at the late AGB or early post-AGB phase, which may affect the morphologies of the remnants of the formerly ejected, approximately spherical shells. Studying objects with such jets is therefore an essential part in understanding the evolutionary process of post-AGB stars.

There are still no fully established theories on jet formation in AGB and post-AGB stars. One of the suggested scenarios depicts a binary system that consists of a star with a thick envelope and its low-mass $\left(<0.3 M_{\odot}\right)$ companion (Nordhaus \& Blackman 2006; Huggins 2007). A torus is first formed due to equatorially enhanced mass loss. The jet is launched after that phase. The launching jet power might come from the magnetocentrifugal force, as is the case of young stellar objects (YSOs; e.g., Frank \& Blackman 2004). For oxygen-rich stars (i.e., intermediate-mass evolved stars with more oxygen than carbon atoms), there is a class of objects called the "water fountains (WFs)" that exhibit a special type of jets: the small in scale $(<1000 \mathrm{AU})$, high-velocity $\left(\geqslant 50 \mathrm{~km} \mathrm{~s}^{-1}\right)$, and strongly collimated bipolar jets. The name comes from the fact that those jets can be traced by $\mathrm{H}_{2} \mathrm{O}$ maser emission. From the point of view of spectroscopy, an object is proposed to be a WF if its $\mathrm{H}_{2} \mathrm{O}$ maser emission spectrum shows a larger velocity coverage than that of its $1612 \mathrm{MHz}$ OH maser (see Imai 2007; Desmurs 2012, for a WF review). It is because the typical $\mathrm{OH}$ double-peaked line shape reveals the terminal expansion velocity (normally $\leqslant 25 \mathrm{~km} \mathrm{~s}^{-1}$ ) of the spherically expanding envelope formed by the AGB mass loss. A larger spectral coverage of $\mathrm{H}_{2} \mathrm{O}$ will therefore imply an outflow with velocity exceeding that of the spherical envelope. It is confirmed by high-angular-resolution interferometric observations of the $22 \mathrm{GHz} \mathrm{H}_{2} \mathrm{O}$ maser line that this phenomenon is caused by the existence of high-velocity bipolar jets (e.g., Imai et al. 2002; Yung et al. 2011). Most of the WF $\mathrm{H}_{2} \mathrm{O}$ maser spectra have a velocity coverage larger than $50 \mathrm{~km} \mathrm{~s}^{-1}$, reaching up to $200-300 \mathrm{~km} \mathrm{~s}^{-1}$. WFs are often regarded as objects that have just started to depart from spherical symmetry. For this reason, WFs are commonly seen as young post-AGB stars (e.g., Suárez et al. 2008; Walsh et al. 2009; Desmurs 2012). In addition to WFs, some OH objects (without $\mathrm{H}_{2} \mathrm{O}$ maser detections) are found to have bipolar jets as well (Zijlstra et al. 2001). These objects usually show rather irregular $\mathrm{OH}$ maser profiles with large velocity coverages (about $30-80 \mathrm{~km} \mathrm{~s}^{-1}$ ). The irregular profiles imply that these objects are more evolved than usual AGB stars (Deacon et al. 2004). 
However, there are also exceptional cases of AGB stars with aspherical structures: W 43A (Imai et al. 2002), X Her (Hirano et al. 2004), and V Hya (Nakashima 2005) are examples of AGB stars with bipolar jets.

Even though the exact evolutionary phase for the jet to be launched is uncertain, it is clear from the above studies that jets play an important role in changing the morphology of envelopes at later stages of stellar evolution. In order to understand the underlying process of such a shaping mechanism, we need to obtain a larger sample of late AGB/post-AGB stars, especially those associated with high-velocity jets such as the WFs. In our previous $\mathrm{H}_{2} \mathrm{O}$ maser survey (Yung et al. 2013, hereafter Paper I), we have shown that the $A K A R I$ two-color diagram could be useful in selecting AGB and post-AGB star candidates, providing an alternative way of object selection besides the wellknown IRAS two-color diagram (van der Veen \& Habing 1988) that has been used in many major surveys (see Paper I for a summary of surveys). We have found four candidates of "lowvelocity" WFs, which are objects that have a small $\mathrm{H}_{2} \mathrm{O}$ maser velocity coverage $\left(\sim 30 \mathrm{~km} \mathrm{~s}^{-1}\right)$, but still fulfill the other WF criteria (i.e., the $\mathrm{H}_{2} \mathrm{O}$ coverage is larger than that of $\mathrm{OH}$, and the IRAS colors are very red). These could be immature WFs, but their true status has to be confirmed by observations with high angular resolution, e.g., very long baseline interferometric observations of maser lines, or infrared imagings with adaptive optics.

In this paper, we further explore potentially reliable indicators for the evolutionary status of evolved stars, in particular for those at the late AGB/post-AGB phase. We have selected 100 evolved star candidates in the late AGB/post-AGB phase by using the $A K A R I$ color criteria suggested in Paper I. Then, we searched for the $\mathrm{OH}$ and $\mathrm{H}_{2} \mathrm{O}$ maser emission from these objects because those maser lines can be a probe of high-velocity jets. Finally, we study the object distribution on the $Q 1-Q 2$ diagram (which is an extinction-free infrared tool proposed by Messineo et al. 2012; see Section 4.1) and also the AKARI two-color diagram. The former reflects the near-infrared properties of the objects, while the latter is predominantly affected by the farinfrared emission. Observational details of this work including the source selection are given in Section 2; the results are presented in Section 3, followed by the discussion in Section 4. Main conclusions are summarized in Section 5.

\section{OBJECT SELECTION AND MASER OBSERVATIONS}

\subsection{Object Selection}

Table 1 displays parameters of the 108 objects observed in this project. Most of the objects were selected from the AKARI Point Source Catalogue (Kataza et al. 2010; Yamamura et al. 2010), according to their [09]-[18] and [18]-[65] colors. In Paper I, we have defined the empirical "post-AGB star" color region by $0.5 \leqslant[09]-[18] \leqslant 4.5$ and $-0.5 \leqslant[18]-[65] \leqslant 2$, where $[m]-[n]=2.5 \log \left(F_{n} / F_{m}\right)$, with $F_{m}$ and $F_{n}$ representing the band fluxes at $m$ and $n \mu \mathrm{m}$, respectively. However, this region still suffers from contamination by YSOs. Therefore, we have also checked the mid-infrared images of all the objects during the selection, in order to exclude obvious YSO candidates. Evolved stars usually appear as point sources in mid-infrared images, e.g., in images taken with the Midcourse Space Experiment $(M S X)$ and Wide-field Infrared Survey Explorer (WISE). On the contrary, YSOs are often embedded in comparatively large scale nebulosities that show extended emission features at midinfrared wavelengths. In addition to these new objects that were not observed before in the $1612 \mathrm{MHz} \mathrm{OH}$ nor in the $22 \mathrm{GHz}$ $\mathrm{H}_{2} \mathrm{O}$ maser lines, some known $\mathrm{H}_{2} \mathrm{O}$ maser sources (especially those newly reported in Paper I) with no reported $\mathrm{OH}$ maser counterparts were included. We have also re-visited a few known WFs and low-velocity WF candidates. The declinations of the targets are limited to $\delta>-25^{\circ}$ because of the telescope location. Owing to limited observing time, not all objects were observed in both lines (see Table 1).

\subsection{Maser Observations and Data Reduction}

The $\mathrm{OH}$ and $\mathrm{H}_{2} \mathrm{O}$ maser observations were carried out with the Effelsberg $100 \mathrm{~m}$ radio telescope from 2012 October 11 to 18. For the $\mathrm{OH}$ observations, an 1.3-1.7 GHz HEMT receiver was used with a fast-Fourier-transform (FFT) spectrometer as backend. The frequency coverage of the spectrometer was $100 \mathrm{MHz}$. The central frequency was set to $1640.0 \mathrm{MHz}$ so that three of the four ${ }^{2} \Pi_{3 / 2} J=3 / 2,18 \mathrm{~cm} \Lambda$-doublet lines were covered. The adopted rest frequencies of the $\mathrm{OH}$ lines were $1612.2310 \mathrm{MHz}$ for the satellite line, and 1665.4018, $1667.3590 \mathrm{MHz}$ for the two main lines (Lovas 2004). The FWHM of the beam was about $8^{\prime}$. With 32,768 spectral channels, the corresponding channel spacing for the three target frequencies was between $0.5 \mathrm{~km} \mathrm{~s}^{-1}$ and $0.6 \mathrm{~km} \mathrm{~s}^{-1}$. For the $\mathrm{H}_{2} \mathrm{O}$ observation, an 18-26 GHz HEMT receiver was used with another FFT spectrometer. The frequency coverage of the spectrometer was $500 \mathrm{MHz}$, and the central frequency was set to $22.235080 \mathrm{GHz}$, the rest frequency of the $6_{16} \rightarrow 5_{23}$ transition line of $\mathrm{H}_{2} \mathrm{O}$ (Lovas 2004). The FWHM of the beam was about $40^{\prime \prime}$. The number of spectral channels was again 32,768 , so the channel spacing was about $0.8 \mathrm{~km} \mathrm{~s}^{-1}$. Velocity resolutions are coarser than the channel spacing, by $16 \%$. The scale of the local-standard-of-rest velocity $\left(V_{\mathrm{LSR}}\right)$ for both $\mathrm{OH}$ and $\mathrm{H}_{2} \mathrm{O}$ observations has been confirmed to be accurate by comparisons with spectra from known sources.

An ON/OFF cycle of 2 minutes was used in a positionswitching mode. For $\mathrm{OH}$ masers, the OFF-position was $1^{\circ}$ west in azimuth from the ON-position. For $\mathrm{H}_{2} \mathrm{O}$ masers, the OFFposition was set to $-75 \mathrm{~s}$ with respect to the $\mathrm{ON}$-position along right ascension. This option was chosen because it kept the OFF-position exactly on the same track as the ON-position. ${ }^{5}$ The observing time for each source was about 6-20 minutes, with the exception of IRAS 19356+0754, which was observed for $6 \mathrm{hr}$. The long integration time was needed to confirm the weak line components from this object (see Section 3.2). The root-mean-square (rms) noise level ranges from 0.001 to $0.1 \mathrm{Jy}$ for both $\mathrm{OH}$ and $\mathrm{H}_{2} \mathrm{O}$ maser observations. Pointing was calibrated every $2-3 \mathrm{hr}$ by doing two-point cross scans on bright quasars with strong continuum emission. The typical pointing accuracy is about $5^{\prime \prime}$. Flux calibration was obtained using pointing sources with known flux densities (see, Ott et al. 1994).

Data reduction were performed with the Continuum and Line Analysis Single-dish Software package. ${ }^{6}$ Individual scans on each object were inspected by eye, and those with obvious artifacts were discarded. The remaining scans were then averaged. The baseline of each spectrum was fit by a low order (first-third) polynomial and subtracted, using channels free of emission features.

\footnotetext{
5 https://eff100mwiki.mpifr-bonn.mpg.de

6 http://www.iram.fr/IRAMFR/GILDAS
} 
Table 1

Parameters of the Objects Observed

\begin{tabular}{|c|c|c|c|c|c|c|c|c|c|}
\hline Object & Other Name & R.A. ${ }^{a}$ & Decl. $^{\mathrm{a}}$ & $\mathrm{AC}_{12}{ }^{\mathrm{b}}$ & $\mathrm{AC}_{23}{ }^{\mathrm{b}}$ & $Q 1^{\mathrm{c}}$ & $Q 2^{\mathrm{c}}$ & $\mathrm{OH}^{\mathrm{d}}$ & $\mathrm{H}_{2} \mathrm{O}^{\mathrm{d}}$ \\
\hline $0038592+592746$ & INS2001 J003859.4+592749 & 003859.28 & +592746.9 & 0.75 & 1.35 & -0.49 & -9.84 & $\ldots$ & $\mathrm{N}$ \\
\hline $0122182+634055$ & $\ldots$ & 012218.28 & +634055.3 & 0.56 & 1.31 & -0.55 & -9.39 & $\ldots$ & $\mathrm{N}$ \\
\hline $0128404+632737$ & $\ldots$ & 012840.47 & +632737.9 & 0.60 & 1.76 & -0.62 & -9.42 & $\ldots$ & $\mathrm{N}$ \\
\hline $0253373+691539$ & IRAS $02490+6903$ & 025337.39 & +691539.2 & 1.54 & 1.63 & -4.10 & $\ldots$ & $\ldots$ & $\mathrm{N}$ \\
\hline $0358076+624425$ & 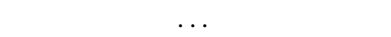 & 035807.65 & +624425.8 & 0.70 & 1.06 & -1.13 & $\ldots$ & $\ldots$ & $\mathrm{N}$ \\
\hline $0413220+501428$ & IRAS $04096+5006$ & 041322.07 & +501428.2 & 0.66 & 1.61 & -1.34 & -9.70 & $\ldots$ & $\mathrm{N}$ \\
\hline $0433014+343840$ & IRAS $04297+3432$ & 043301.45 & +343840.6 & 1.12 & 0.37 & -0.78 & $\ldots$ & $\ldots$ & $\mathrm{N}$ \\
\hline $0536468+314600$ & IRAS $05335+3144$ & 053646.88 & +314600.2 & 0.94 & 1.36 & 0.02 & -7.73 & $\ldots$ & $\mathrm{N}$ \\
\hline $0540502+340241$ & $\ldots$ & 054050.22 & +340241.3 & 0.82 & 1.71 & 0.16 & $\ldots$ & $\ldots$ & $\mathrm{N}$ \\
\hline $0547450+003842$ & 2MASS J05474500+0038418 & 054745.00 & +003842.1 & 1.02 & 1.18 & -0.50 & $\ldots$ & $\ldots$ & $\mathrm{N}$ \\
\hline $0608452+130841$ & $\ldots$ & 060845.28 & +130841.3 & 1.53 & 1.45 & -3.06 & -11.76 & $\ldots$ & $\mathrm{N}$ \\
\hline IRAS $16030-0634$ & $\ldots$ & 160546.33 & -064227.9 & -0.46 & $\ldots$ & -0.16 & $\ldots$ & $\mathrm{N}$ & $\mathrm{N}$ \\
\hline IRAS $16131-0216$ & $\ldots$ & 161547.66 & -022331.9 & -0.64 & $\ldots$ & 0.28 & $\ldots$ & $\mathrm{N}$ & $\mathrm{N}$ \\
\hline IRAS $17055-0216$ & $\ldots$ & 170810.20 & -022021.0 & -0.22 & $\ldots$ & -0.63 & $\ldots$ & $\mathrm{N}$ & $\mathrm{Y}$ \\
\hline IRAS $17132-0744$ & $\ldots$ & 171556.40 & -074733.0 & $\ldots$ & $\ldots$ & $\ldots$ & $\ldots$ & $\mathrm{N}$ & $\mathrm{Y}$ \\
\hline IRAS $17171-0843$ & $\ldots$ & 171953.45 & -084659.7 & -0.11 & $\ldots$ & -0.70 & $\ldots$ & $\ldots$ & $\mathrm{Y}$ \\
\hline IRAS 17193-0601 & $\ldots$ & 172202.30 & -060413.0 & -0.46 & $\ldots$ & -0.05 & $\ldots$ & $\mathrm{N}$ & $\mathrm{N}$ \\
\hline IRAS $17343+1052$ & $\ldots$ & 173644.45 & +105107.0 & -0.72 & $\ldots$ & 0.01 & $\ldots$ & $\ldots$ & $\mathrm{Y}$ \\
\hline $1741385-241435$ & IRAS $17385-2413$ & 174138.52 & -241435.8 & 1.22 & -0.90 & 0.40 & -24.21 & $\ldots$ & $\mathrm{N}$ \\
\hline $1750356-203743$ & IRAS $17476-2036$ & 175035.60 & -203743.5 & 0.58 & -0.47 & -0.72 & -7.88 & $\mathrm{~N}$ & $\mathrm{~N}$ \\
\hline $1752536-184100$ & $\ldots$ & 175253.68 & -184100.8 & 0.74 & -1.44 & -6.64 & -16.10 & $\ldots$ & $\mathrm{N}$ \\
\hline $1807272-194639$ & IRAS 18044-1947 & 180727.26 & -194639.3 & 0.92 & -1.09 & -1.43 & -11.22 & $\mathrm{Y}$ & $\mathrm{N}$ \\
\hline IRAS $18056-1514$ & $\ldots$ & 180828.40 & -151330.0 & 0.43 & -0.96 & 0.37 & -18.59 & $\mathrm{Y}$ & $\mathrm{Y}$ \\
\hline IRAS 18099-1449 & $\cdots$ & 181247.37 & -144850.0 & -0.68 & $\cdots$ & -0.08 & -5.11 & $\mathrm{~N}$ & $\mathrm{Y}$ \\
\hline IRAS $18100-1250$ & $\ldots$ & 181250.49 & -124944.8 & -0.39 & $\ldots$ & -0.17 & -5.68 & $\mathrm{~N}$ & $\mathrm{Y}$ \\
\hline IRAS $18117-1625$ & $\ldots$ & 181438.70 & -162439.0 & 0.04 & $\ldots$ & -1.21 & -8.05 & $\mathrm{Y}$ & $\mathrm{Y}$ \\
\hline IRAS $18118-1615$ & $\ldots$ & 181441.35 & -161403.0 & 0.47 & $\ldots$ & -1.09 & -9.99 & $\mathrm{Y}$ & $\mathrm{N}$ \\
\hline IRAS $18127-1516$ & $\ldots$ & 181539.90 & -151513.0 & $\ldots$ & $\ldots$ & -1.10 & -10.05 & $\mathrm{Y}$ & $\mathrm{Y}$ \\
\hline $1824037+063625$ & IRAS $18216+0634$ & 182403.72 & +063625.8 & 0.85 & -1.33 & -1.19 & $\ldots$ & $\mathrm{Y}$ & $\mathrm{N}$ \\
\hline $1824288-155108$ & IRAS 18216-1552 & 182428.88 & -155109.0 & 0.22 & -1.01 & -3.39 & -15.35 & $\ldots$ & $\mathrm{N}$ \\
\hline IRAS $18251-1048$ & $\ldots$ & 182756.30 & -104658.0 & 0.80 & $\ldots$ & -1.57 & -9.80 & $\mathrm{Y}$ & $\ldots$ \\
\hline IRAS 18286-0959 & $\ldots$ & 183122.93 & -095721.7 & 0.80 & 0.13 & 0.27 & -29.35 & $\mathrm{Y}$ & $\mathrm{Y}$ \\
\hline $\mathrm{OH} 16.3-3.0$ & TVH89 313 & 183131.51 & -160846.5 & 0.83 & -0.62 & -0.76 & -16.30 & $\mathrm{Y}$ & $\mathrm{Y}$ \\
\hline IRAS $18362-0521$ & $\ldots$ & 183857.47 & -051828.0 & $\ldots$ & $\ldots$ & -0.10 & -5.51 & $\ldots$ & $\mathrm{N}$ \\
\hline $1838595-052024$ & IRAS $18363-0523$ & 183859.57 & -052024.0 & 0.41 & -1.40 & -0.27 & -5.15 & $\mathrm{Y}$ & $\mathrm{N}$ \\
\hline $1848010+000448$ & IRAS 18454+0001 & 184801.09 & +000448.6 & 4.08 & 1.30 & -0.19 & -12.53 & $\ldots$ & $\mathrm{N}$ \\
\hline IRAS $18455+0448$ & $\ldots$ & 184802.30 & +045130.5 & 1.03 & -0.88 & -1.81 & -19.73 & $\ldots$ & $\mathrm{Y}$ \\
\hline $1854158+011501$ & $\ldots$ & 185415.85 & +011501.8 & 0.84 & 1.57 & -7.00 & -11.79 & $\mathrm{Y}$ & $\mathrm{N}$ \\
\hline $1854250+004958$ & MSX6C G034.0126-00.2832 & 185425.10 & +004958.2 & 0.69 & 1.41 & -1.40 & -10.46 & $\mathrm{Y}$ & $\mathrm{N}$ \\
\hline IRAS $18587+0521 \mathrm{~A}$ & $\ldots$ & 190108.43 & +052548.0 & -0.05 & $\ldots$ & 0.08 & -3.75 & $\ldots$ & $\mathrm{N}$ \\
\hline IRAS 18587+0521 & $\ldots$ & 190110.70 & +052546.0 & $\ldots$ & $\ldots$ & 0.58 & $\ldots$ & $\mathrm{Y}$ & $\ldots$ \\
\hline IRAS $18587+0521 B$ & $\ldots$ & 190112.40 & +052543.4 & 1.95 & $\ldots$ & 0.27 & -16.12 & $\ldots$ & $\mathrm{Y}$ \\
\hline IRAS 18596+0605 & $\ldots$ & 190204.69 & +061009.5 & 0.04 & $\ldots$ & -0.28 & -5.78 & $\ldots$ & $\mathrm{N}$ \\
\hline $1904448+042318$ & SSTGLMC G038.3546-00.9519 & 190444.90 & +042318.2 & 1.10 & 1.41 & -4.55 & -17.93 & $\mathrm{Y}$ & $\mathrm{N}$ \\
\hline IRAS 19027+0517 & $\ldots$ & 190514.28 & +052152.2 & 0.35 & $\ldots$ & -0.88 & -13.79 & $\mathrm{Y}$ & $\mathrm{N}$ \\
\hline IRAS 19074+0534 & $\ldots$ & 190954.81 & +053906.9 & 1.04 & 1.37 & -2.18 & -16.56 & $\mathrm{Y}$ & $\mathrm{N}$ \\
\hline IRAS $19085+1038$ & $\ldots$ & 191057.20 & +104338.0 & $\ldots$ & $\ldots$ & 0.19 & $\ldots$ & $\mathrm{N}$ & $\mathrm{N}$ \\
\hline $1911358+133111$ & IRAS $19092+1326$ & 191135.85 & +133111.1 & 1.74 & 0.44 & -1.85 & -17.00 & $\mathrm{~N}$ & $\mathrm{~N}$ \\
\hline $1912477+033435$ & $\ldots$ & 191247.75 & +033435.8 & 3.78 & 0.21 & -0.23 & -12.80 & $\mathrm{~N}$ & $\mathrm{~N}$ \\
\hline $1914408+114449$ & IRAS 19123+1139 & 191440.83 & +114449.4 & 1.21 & 1.15 & -0.90 & -6.73 & $\mathrm{Y}$ & $\mathrm{N}$ \\
\hline IRAS 19134+2131 & $\ldots$ & 191535.19 & +213633.6 & 2.35 & -0.24 & -1.01 & -21.84 & $\mathrm{~N}$ & $\mathrm{Y}$ \\
\hline $1918205+014659$ & V V605 Aql & 191820.57 & +014659.0 & 1.83 & 0.60 & -0.43 & $\ldots$ & $\mathrm{N}$ & $\mathrm{N}$ \\
\hline $1919572+104808$ & IRAS $19175+1042$ & 191957.24 & +104808.8 & 0.84 & -0.36 & -1.73 & -11.84 & $\ldots$ & $\mathrm{Y}$ \\
\hline $1922250+131851$ & IRAS $19201+1313$ & 192225.08 & +131851.6 & 0.87 & 1.97 & -2.33 & -14.00 & $\ldots$ & $\mathrm{N}$ \\
\hline $1922557+202854$ & IRAS 19207+2023 & 192255.78 & +202854.3 & 3.21 & -0.41 & 0.08 & -6.40 & $\mathrm{Y}$ & $\mathrm{N}$ \\
\hline $1923002+151051$ & IRAS $19207+1504$ & 192300.28 & +151051.3 & 0.67 & -0.73 & -1.47 & -15.53 & $\ldots$ & $\mathrm{N}$ \\
\hline $1930003+175601$ & MSX6C G053.2176-00.0808 & 193000.30 & +175601.7 & 1.07 & 1.32 & -1.09 & -7.78 & $\mathrm{Y}$ & $\mathrm{N}$ \\
\hline IRAS 19312+1950 & $\ldots$ & 193324.30 & +195655.0 & 1.08 & 2.32 & 1.63 & -8.42 & $\mathrm{Y}$ & $\mathrm{Y}$ \\
\hline IRAS 19356+0754 & $\ldots$ & 193801.19 & +080133.0 & 1.94 & 0.07 & -1.13 & $\ldots$ & $\mathrm{Y}$ & $\mathrm{Y}$ \\
\hline $1938574+103016$ & IRAS19365+1023 & 193857.42 & +103016.0 & 0.53 & 0.11 & -0.23 & $\ldots$ & $\mathrm{N}$ & $\mathrm{N}$ \\
\hline IRAS 19464+3514 & $\ldots$ & 194815.96 & +352206.1 & 0.20 & -1.80 & -1.17 & $\ldots$ & $\ldots$ & $\mathrm{Y}$ \\
\hline $1951461+272458$ & 2MASS J19514615+2724587 & 195146.20 & +272458.5 & 0.82 & 1.61 & -1.33 & -9.83 & $\mathrm{~N}$ & $\mathrm{Y}$ \\
\hline IRAS $20010+2508$ & $\ldots$ & 200308.30 & +251727.0 & -0.75 & $\ldots$ & -0.24 & -1.90 & $\mathrm{~N}$ & $\mathrm{~N}$ \\
\hline $2003357+284847$ & IRAS $20015+2840$ & 200335.71 & +284847.2 & 1.75 & 1.59 & -0.65 & $\ldots$ & $\mathrm{N}$ & $\mathrm{N}$ \\
\hline $2003599+351617$ & $\ldots$ & 200359.97 & +351617.9 & 0.58 & 1.86 & -0.50 & -8.39 & $\mathrm{~N}$ & $\mathrm{~N}$ \\
\hline
\end{tabular}


Table 1

(Continued)

\begin{tabular}{|c|c|c|c|c|c|c|c|c|c|}
\hline Object & Other Name & R.A. $^{a}$ & Decl. $^{\mathrm{a}}$ & $\mathrm{AC}_{12}{ }^{\mathrm{b}}$ & $\mathrm{AC}_{23}{ }^{\mathrm{b}}$ & $Q 1^{\mathrm{c}}$ & $Q 2^{\mathrm{c}}$ & $\mathrm{OH}^{\mathrm{d}}$ & $\mathrm{H}_{2} \mathrm{O}^{\mathrm{d}}$ \\
\hline IRAS 20021+2156 & & 200417.30 & +220459.0 & -0.27 & & -0.16 & -6.44 & $\mathrm{~N}$ & $\mathrm{Y}$ \\
\hline $2008383+410040$ & IRAS $20068+4051$ & 200838.39 & +410040.4 & 2.22 & 1.92 & 0.14 & -9.79 & $\mathrm{~N}$ & $\mathrm{~N}$ \\
\hline $2009217+271859$ & IRAS $20072+2710$ & 200921.72 & +271859.2 & 0.94 & 1.26 & -0.56 & -7.68 & $\ldots$ & $\mathrm{N}$ \\
\hline $2013142+370536$ & IRAS $20113+3656$ & 201314.22 & +370536.9 & 1.01 & 0.94 & -0.77 & -8.80 & $\ldots$ & $\mathrm{N}$ \\
\hline $2015573+470534$ & IRAS $20144+4656$ & 201557.33 & +470534.5 & 2.97 & 0.60 & -1.11 & & $\mathrm{Y}$ & $\mathrm{N}$ \\
\hline $2020151+364334$ & $\ldots$ & 202015.14 & +364334.5 & 1.10 & 1.58 & -0.98 & -9.59 & $\ldots$ & $\mathrm{N}$ \\
\hline IRAS $20215+6243$ & $\ldots$ & 202220.05 & +625302.2 & -0.56 & $\ldots$ & -0.08 & $\ldots$ & $\mathrm{N}$ & $\mathrm{N}$ \\
\hline $2029222+403543$ & IRAS $20275+4025$ & 202922.22 & +403543.5 & 1.20 & 1.71 & -2.40 & -15.46 & $\ldots$ & $\mathrm{N}$ \\
\hline IRAS $20305+6246$ & & 203126.54 & +625649.8 & -0.89 & $\ldots$ & -0.22 & $\ldots$ & $\mathrm{N}$ & $\mathrm{N}$ \\
\hline $2033464+450840$ & MSX6C G083.3609+02.9902 & 203346.48 & +450840.4 & 1.31 & -0.24 & -1.63 & -17.41 & $\ldots$ & $\mathrm{N}$ \\
\hline $2040444+465322$ & IRAS 20390+4642 & 204044.45 & +465322.4 & 0.56 & 0.97 & -0.97 & -10.08 & $\mathrm{~N}$ & $\mathrm{~N}$ \\
\hline $2048044+390459$ & IRAS $20461+3853$ & 204804.41 & +390459.7 & 1.83 & -0.46 & 0.02 & -11.73 & $\mathrm{~N}$ & $\mathrm{~N}$ \\
\hline $2048166+342724$ & IRAS $20462+3416$ & 204816.64 & +342724.4 & 4.38 & 0.29 & -0.12 & $\ldots$ & $\mathrm{N}$ & $\mathrm{N}$ \\
\hline $2050135+594551$ & IRAS $20490+5934$ & 205013.58 & +594551.2 & 1.61 & 0.63 & -0.58 & $\ldots$ & $\mathrm{N}$ & $\mathrm{N}$ \\
\hline $2053379+445807$ & MSX6C G085.3935+00.1268 & 205337.98 & +445807.4 & 0.91 & -0.65 & -5.98 & -26.82 & $\ldots$ & $\mathrm{N}$ \\
\hline $2057130+482200$ & IRAS $20555+4810$ & 205713.08 & +482200.3 & 0.72 & 1.72 & -0.54 & -15.92 & $\ldots$ & $\mathrm{N}$ \\
\hline $2100253+523017$ & V V2495 Cyg & 210025.34 & +523017.6 & 1.34 & 1.75 & $\ldots$ & $\ldots$ & $\ldots$ & $\mathrm{N}$ \\
\hline $2101550+495135$ & IRAS $21002+4939$ & 210155.02 & +495135.5 & 0.77 & 0.97 & -0.58 & -7.37 & $\ldots$ & $\mathrm{N}$ \\
\hline $2117391+685509$ & IRAS $21169+6842$ & 211739.18 & +685509.5 & 1.13 & 0.60 & -0.62 & $\ldots$ & $\ldots$ & $\mathrm{N}$ \\
\hline $2122090+492624$ & $\ldots$ & 212209.06 & +492624.5 & 0.59 & 0.38 & -0.81 & -9.28 & $\ldots$ & $\mathrm{N}$ \\
\hline IRAS $21509+6234$ & $\ldots$ & 215219.37 & +624839.5 & -0.41 & $\ldots$ & 0.07 & $\ldots$ & $\mathrm{N}$ & $\mathrm{N}$ \\
\hline IRAS $21522+6018$ & $\ldots$ & 215346.10 & +603214.2 & -0.55 & $\ldots$ & -0.14 & $\ldots$ & $\mathrm{N}$ & $\mathrm{Y}$ \\
\hline $2155455+575106$ & IRAS $21541+5736$ & 215545.55 & +575106.6 & 1.31 & 1.96 & -0.79 & -8.98 & $\ldots$ & $\mathrm{N}$ \\
\hline IRAS $21563+5630$ & $\ldots$ & 215801.30 & +564449.6 & -0.58 & -1.90 & -0.32 & -4.45 & $\mathrm{~N}$ & $\mathrm{~N}$ \\
\hline $2158358+585722$ & 2MASS J21583590+5857227 & 215835.81 & +585722.8 & 0.79 & 1.59 & -1.51 & -9.08 & $\ldots$ & $\mathrm{N}$ \\
\hline $2204124+530401$ & IRAS $22023+5249$ & 220412.45 & +530402.0 & 3.53 & -0.17 & -0.22 & -14.38 & $\ldots$ & $\mathrm{N}$ \\
\hline IRAS $22097+5647$ & & 221131.88 & +5702 17.4 & -0.12 & -2.72 & -0.15 & -4.69 & $\mathrm{Y}$ & $\mathrm{Y}$ \\
\hline $2219055+613616$ & IRAS $22174+6121$ & 221905.52 & +613616.1 & 0.63 & 1.34 & -0.70 & -10.34 & $\ldots$ & $\mathrm{N}$ \\
\hline $2219520+633532$ & IRAS $22182+6320$ & 221952.05 & +633532.4 & 0.68 & 1.18 & -0.74 & $\ldots$ & $\ldots$ & $\mathrm{N}$ \\
\hline $2233550+653918$ & $\ldots$ & 223355.02 & +653918.5 & 1.12 & 1.73 & -6.28 & $\ldots$ & $\ldots$ & $\mathrm{N}$ \\
\hline IRAS $22394+6930$ & $\ldots$ & 224059.80 & +694614.7 & -0.63 & $\ldots$ & -0.08 & $\ldots$ & $\mathrm{Y}$ & Y \\
\hline IRAS $22394+5623$ & $\ldots$ & 224127.10 & +563908.0 & -0.71 & $\ldots$ & 0.02 & -2.58 & $\ldots$ & $\mathrm{N}$ \\
\hline $2251389+515042$ & IRAS $22495+5134$ & 225138.97 & +515042.7 & 3.60 & -0.22 & -0.24 & $\ldots$ & $\ldots$ & $\mathrm{N}$ \\
\hline $2259442+585956$ & IRAS $22576+5843$ & 225944.21 & +585956.2 & 1.36 & 1.94 & -1.62 & $\ldots$ & $\ldots$ & $\mathrm{N}$ \\
\hline $2303421+614741$ & $\ldots$ & 230342.15 & +614741.4 & 0.86 & 1.37 & -1.39 & -17.34 & $\ldots$ & $\mathrm{Y}$ \\
\hline $2312291+612534$ & IRAS $23103+6109$ & 231229.16 & +612534.1 & 1.69 & 1.53 & 0.57 & -20.58 & $\ldots$ & $\mathrm{N}$ \\
\hline $2317522+580511$ & IRAS $23156+5748$ & 231752.22 & +580511.2 & 1.43 & 1.16 & -1.05 & -9.27 & $\ldots$ & $\mathrm{N}$ \\
\hline $2335128+610005$ & IRAS $23328+6043$ & 233512.84 & +610005.4 & 0.97 & 1.80 & -2.13 & -9.73 & $\ldots$ & $\mathrm{N}$ \\
\hline $2341559+641512$ & IRAS $23395+6358$ & 234155.98 & +641512.5 & 0.76 & 1.63 & -0.34 & -7.54 & $\ldots$ & $\mathrm{N}$ \\
\hline $2346058+632312$ & IRAS $23436+6306$ & 234605.81 & +632312.8 & 0.95 & 1.19 & -0.27 & -10.85 & $\ldots$ & $\mathrm{N}$ \\
\hline IRAS $23489+6235$ & $\ldots$ & 235127.28 & +625147.1 & -1.44 & $\ldots$ & -0.43 & -1.84 & $\ldots$ & $\mathrm{N}$ \\
\hline IRAS $23554+5612$ & $\ldots$ & 235801.32 & +562913.4 & -0.57 & -2.19 & -0.41 & $\ldots$ & $\ldots$ & $\mathrm{N}$ \\
\hline IRAS $23561+6037$ & $\ldots$ & 235838.70 & +605348.0 & -0.78 & $\ldots$ & 0.06 & -3.13 & $\ldots$ & $\mathrm{N}$ \\
\hline
\end{tabular}

Notes.

a J2000.0.

${ }^{\mathrm{b}} \mathrm{AC}_{12}$ and $\mathrm{AC}_{23}$ represent the AKARI [09]-[18] and [18]-[65] colors, respectively. See Section 2.1 for the definition of color.

c $Q 1$ and $Q 2$ parameters are defined in Messineo et al. (2012); see Section 4.1.

d Detection of $\mathrm{OH} / \mathrm{H}_{2} \mathrm{O}$ maser emission in the current observation is indicated by "Y"; non-detections are indicated by "N." A blank entry means the object is not observed.

\section{RESULTS}

\subsection{Overview of the $\mathrm{OH}$ and $\mathrm{H}_{2} \mathrm{O}$ Maser Detections}

Figure 1 shows the spectra for objects only with $\mathrm{OH}$ maser detections, while Figure 2 is for $\mathrm{H}_{2} \mathrm{O}$ masers only. For objects with both $\mathrm{OH}$ and $\mathrm{H}_{2} \mathrm{O}$ masers detected, their velocity-aligned spectra are shown in Figure 3. Table 1 summarizes the coordinates and infrared colors of the objects that have $\mathrm{OH}$ and/or $\mathrm{H}_{2} \mathrm{O}$ detections. The corresponding spectral parameters of all the detections and non-detections are presented in Tables 2-5. Amongst 108 selected objects, 53 were observed in $\mathrm{OH}$ (which includes the 1612, 1665, and $1667 \mathrm{MHz}$ maser lines), with 24 detections. There are 16 new $1612 \mathrm{MHz}, 9$ new $1665 \mathrm{MHz}$, and 11 new $1667 \mathrm{MHz}$ detections. Some of these newly detected lines originate from the same objects where previously other $\mathrm{OH}$ maser lines have already been reported. For the $\mathrm{H}_{2} \mathrm{O}$ maser line at $22 \mathrm{GHz}, 106$ objects were observed with 24 detections (12 new). The detection rates of both $\mathrm{OH}$ and $\mathrm{H}_{2} \mathrm{O}$ masers agree with some previous maser surveys on post-AGB stars (see Habing 1996 , for a discussion on the detection rates), e.g., $\sim 40 \%$ for OH masers (te Lintel Hekkert \& Chapman 1996), and 25\% for $\mathrm{H}_{2} \mathrm{O}$ masers (Valdettaro et al. 2001; Deacon et al. 2007).

Similar to the results of previous surveys such as those of te Lintel Hekkert et al. (1989) and te Lintel Hekkert (1991), 

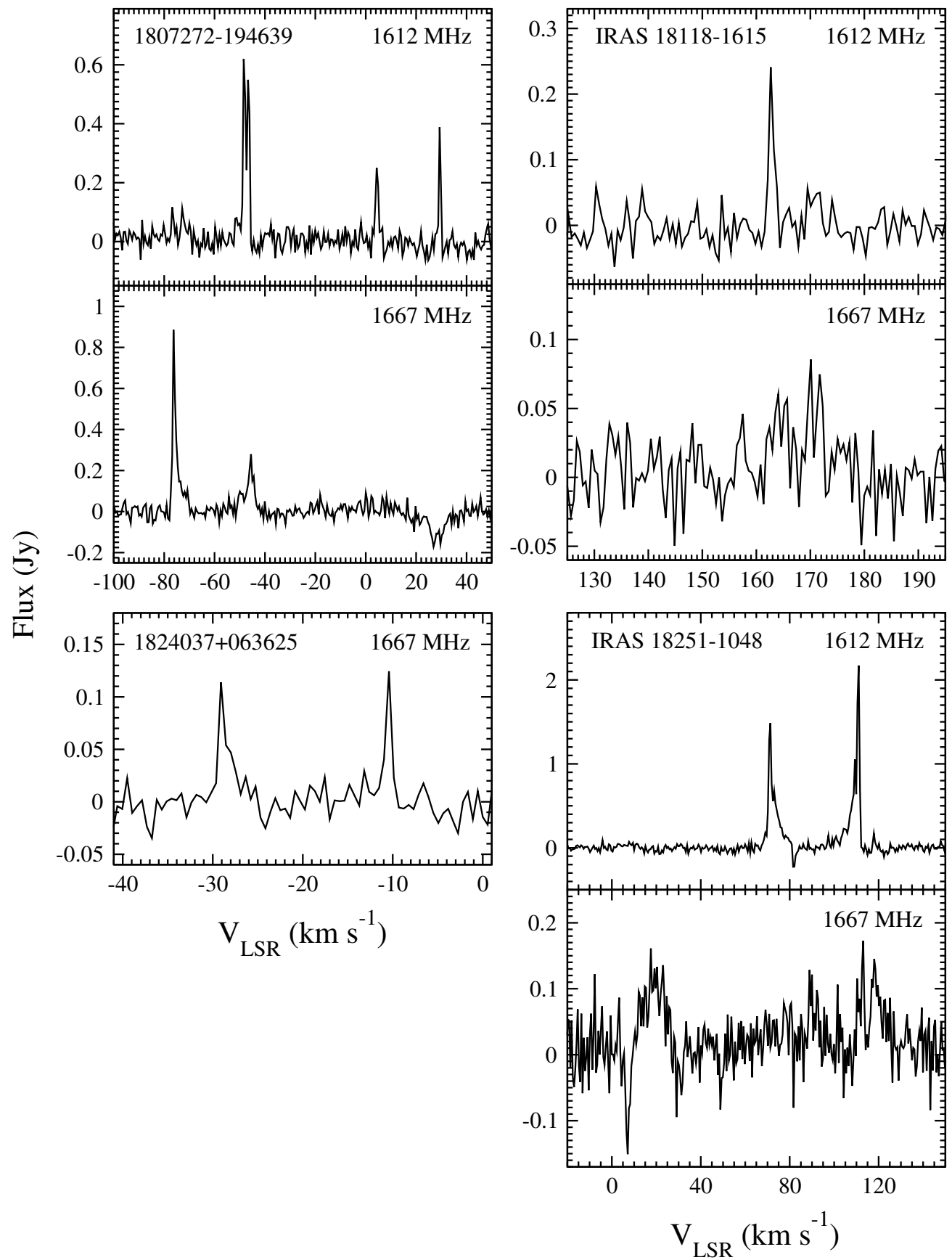

Figure 1. Spectra of objects with $\mathrm{OH}$ maser detections only.

the majority of the $\mathrm{OH}$ spectra show a double-peaked profile at $1612 \mathrm{MHz}$ (Figure 1). This is a common characteristic for Type II OH/IR stars, which are classified by their IRAS colors: $-0.30<[12]-[25]<-0.08$ (Habing 1996). The double-peaked emission profile features two $1612 \mathrm{MHz}$ peaks that reveal the line-of-sight velocities of the approaching and receding sides of the spherically expanding envelope. The velocity halfway between the peaks is taken as the systemic velocity of the star. The 1665 and $1667 \mathrm{MHz}$ main lines usually show similar double-peak profiles, but in most cases they are fainter than those of the $1612 \mathrm{MHz}$ satellite line. On the other hand, there are three objects in our observations with only the main lines detected, namely, 1824037+063625, 1914408+114449, and IRAS 22097+5647. In particular, IRAS
$22097+5647$ belongs to the Type I OH/IR stars with $-0.45<$ [12]-[25] $<-0.30$ (Habing 1996). The $\mathrm{OH}$ emission profile from these stars usually shows only the main lines; occasionally the satellite line is also found but at a much weaker level. The profiles of the main lines usually have an irregular line shape, because the main lines originate from the accelerating region of an expanding envelope, where the gradient in the radial velocity produces the irregular line shape (Habing 1996). We do not have enough information for $1824037+063625$ and 1914408+114449; they could be evolved stars or YSOs. Nonetheless, they are point sources in mid-infrared images, e.g., the $12 \mu \mathrm{m}$ images from the WISE catalog that have an angular resolution of 6..5 (Wright et al. 2010), suggesting that there are no clear star-forming activities around these objects. 

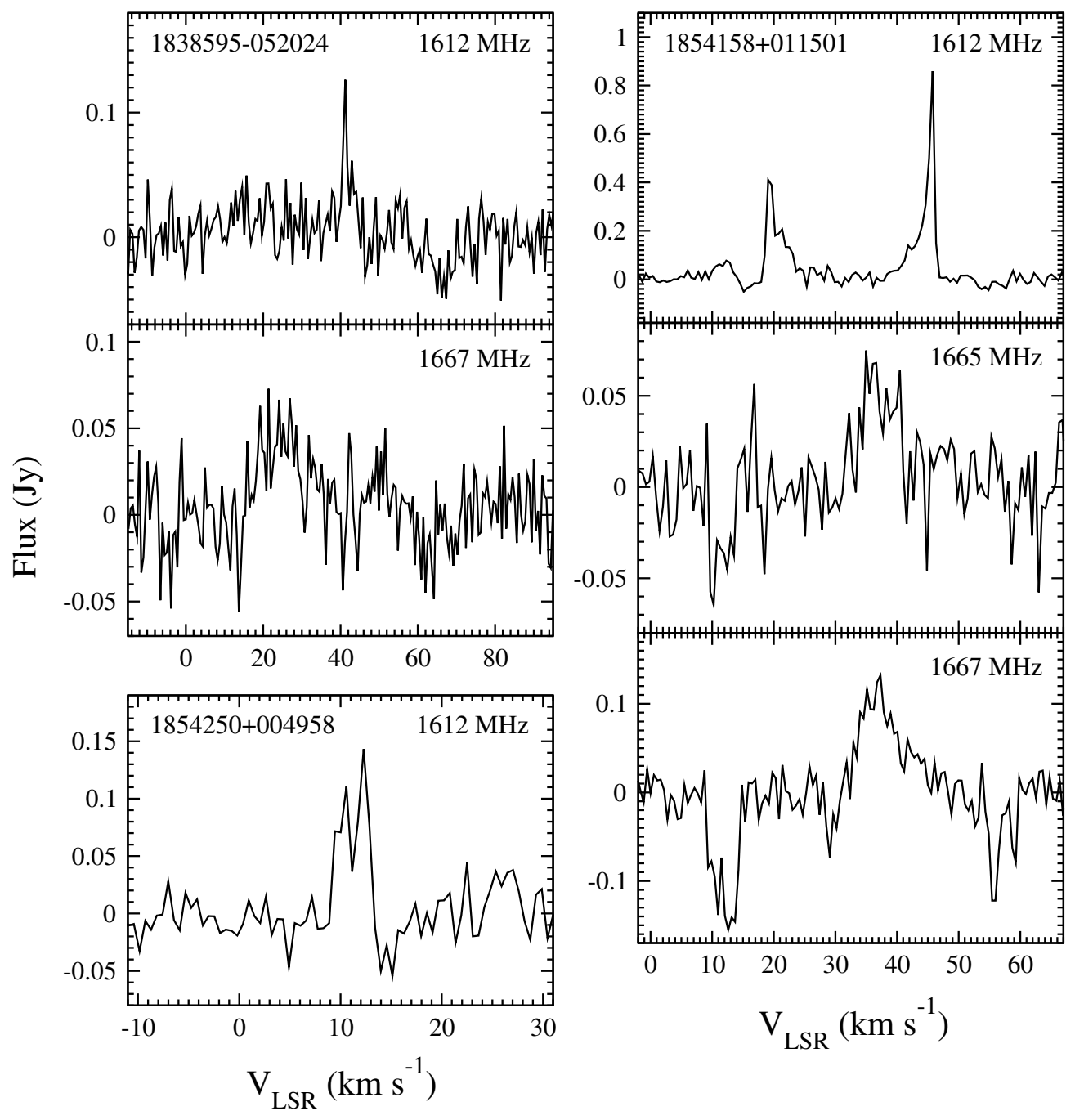

Figure 1. (Continued)

Absorption features are found in several spectra (see Figure 1 and Table 2), but they may be caused by foreground objects (e.g., te Lintel Hekkert \& Chapman 1996), or by some emission that contaminates the OFF-positions.

Most of the obtained $\mathrm{H}_{2} \mathrm{O}$ maser spectra have a double-peaked (with some of them only showing a weak secondary feature) or an irregular profile (Figure 2). It is known that $\mathrm{H}_{2} \mathrm{O}$ masers generally have three common emission profiles: single-peaked, double-peaked, and irregular (e.g., Takaba et al. 1994; Deacon et al. 2007). A single peak at the systemic velocity is quite commonly found in AGB stars with a lower mass-loss rate in the case of a spherically expanding envelope, because the masers are mainly tangentially amplified. When the mass-loss rate increases as the star evolves, the profile will likely become double-peaked because maser amplification along the radial direction is now predominant, where the two peaks come from the approaching and receding sides of the spherical envelope (Takaba et al. 1994). However, the above justification is not necessarily true for all cases because maser line profiles are not solely governed by the mass-loss rate. An irregular profile is often seen in further evolved objects (e.g., the post-AGB star IRAS 15445-5449; Pérez-Sánchez et al. 2011) or YSOs (e.g., W51-IRS2; Morita et al. 1992) because of the development of irregular motions possibly induced by non-spherical (e.g., bipolar) outflow components. Note that the $\mathrm{H}_{2} \mathrm{O}$ maser emission would have a similar or slightly smaller velocity coverage than the $\mathrm{OH}$ maser in most evolved stars with the notable exception of the WFs.

\subsection{Notable Individual Objects}

\subsubsection{Water Fountains}

IRAS 18286-0959. It is a known WF suggested to harbor an episodic precessing jet that produces a "double-helix" jet pattern (Yung et al. 2011). In Paper I, we have already noticed that the $\mathrm{H}_{2} \mathrm{O}$ maser velocity coverage of this object has increased from $220 \mathrm{~km} \mathrm{~s}^{-1}$ to $263 \mathrm{~km} \mathrm{~s}^{-1}$ since its first detection (Deguchi et al. 2007). This time, more components were detected and the resulting coverage is now $\sim 350 \mathrm{~km} \mathrm{~s}^{-1}$ (Figure 3). It is not certain whether the jet really accelerates, or whether it is simply due to maser flux variation so that the new components were not detected in previous observations. For the $\mathrm{OH}$ maser, this object was reported to have a single $1612 \mathrm{MHz}$ feature at $39.5 \mathrm{~km} \mathrm{~s}^{-1}$ (Sevenster et al. 2001). However, here we detected two close peaks at $-0.2 \mathrm{~km} \mathrm{~s}^{-1}$ and $12.3 \mathrm{~km} \mathrm{~s}^{-1}$. The $1612 \mathrm{MHz}$ emission is usually stable on timescales of months or even longer. This is why the disappearance of the $39.5 \mathrm{~km} \mathrm{~s}^{-1}$ peak and the detection 

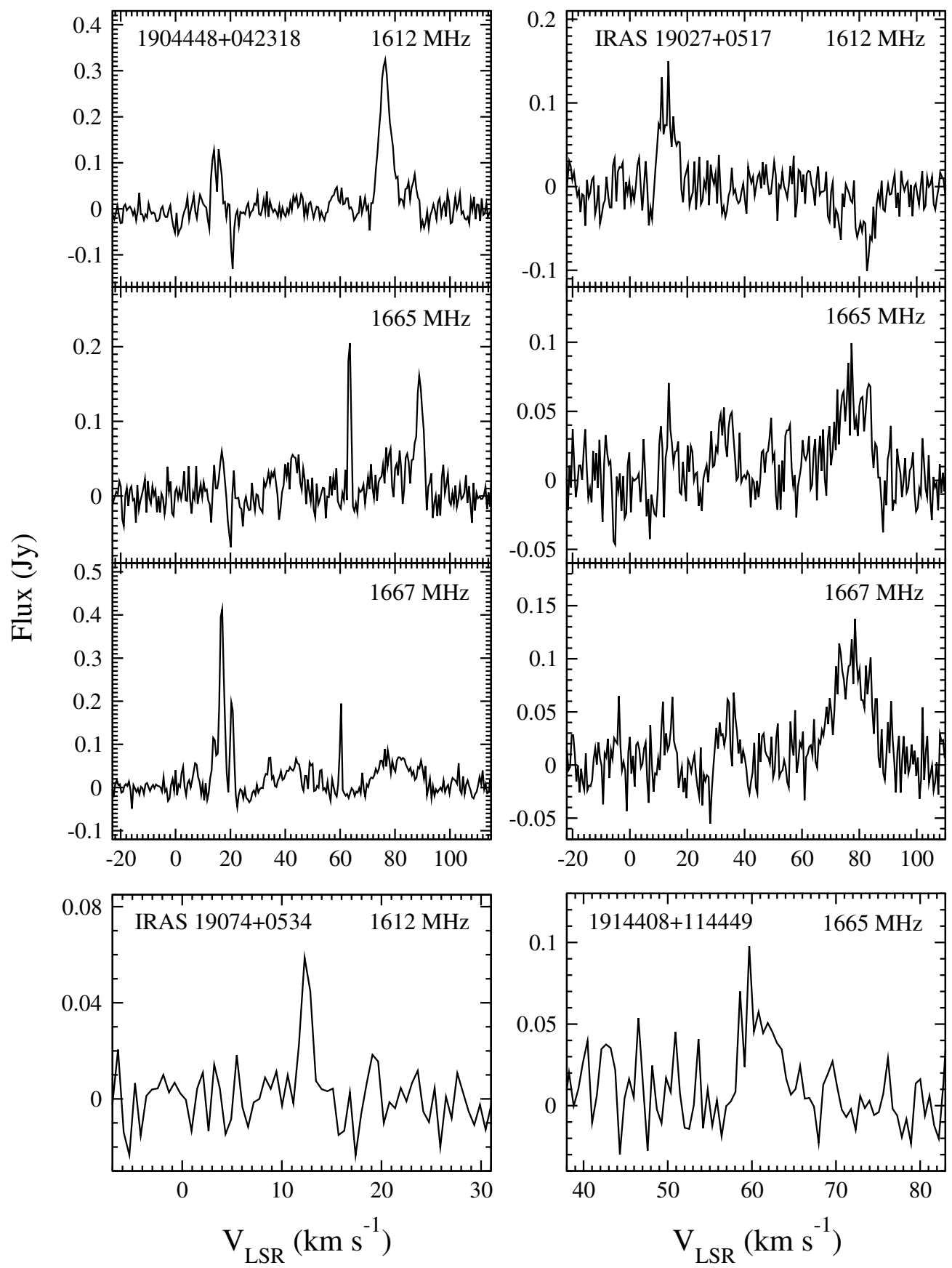

Figure 1. (Continued)

of the new components are unexpected. The reason behind this is unknown, but it might hint to the fact that the $\mathrm{OH}$ shell has been disturbed. Possibilities include the interference from a high-velocity jet, or some turbulent motion due to the existence of a nearby object.

IRAS 19134+2131. The first detailed interferometric study of the $\mathrm{H}_{2} \mathrm{O}$ masers from this WF was presented by Imai et al. (2007). Its $\mathrm{H}_{2} \mathrm{O}$ maser spectrum used to have three peaks at about $-120 \mathrm{~km} \mathrm{~s}^{-1},-40 \mathrm{~km} \mathrm{~s}^{-1}$, and $-10 \mathrm{~km} \mathrm{~s}^{-1}$. All of them were still detected in 2011 (Paper I). This time the most blueshifted peak (i.e., at $-120 \mathrm{~km} \mathrm{~s}^{-1}$ ) disappeared, and the remaining double-peak profile resembles those of normal AGB stars (Figure 2). There has been no $\mathrm{OH}$ maser detection toward this object. A longer exposure time may be needed.
IRAS $19356+0754$. This object could be a new member of the WF class. Its $\mathrm{OH} 1612 \mathrm{MHz}$ maser spectrum has many emission peaks with velocities ranging from $-138 \mathrm{~km} \mathrm{~s}^{-1}$ to $-71 \mathrm{~km} \mathrm{~s}^{-1}$. The large velocity coverage $\left(\sim 67 \mathrm{~km} \mathrm{~s}^{-1}\right)$ and the irregular profile are common for very evolved objects like post-AGB stars or proto-planetary nebulae (PPNe; Zijlstra et al. 2001). The 1665 and $1667 \mathrm{MHz}$ lines also have an irregular profile and span a similar velocity range, but the total flux is smaller than that of the $1612 \mathrm{MHz}$ line. The $\mathrm{H}_{2} \mathrm{O}$ maser spectrum consists of multiple peaks with a total velocity coverage of about $119 \mathrm{~km} \mathrm{~s}^{-1}$ (from $-145 \mathrm{~km} \mathrm{~s}^{-1}$ to $-26 \mathrm{~km} \mathrm{~s}^{-1}$ ), larger than that of the $\mathrm{OH}$ masers. The $\mathrm{H}_{2} \mathrm{O}$ lines are very weak: the strongest peak is only about $0.2 \mathrm{Jy}$. Note that this object was observed in $\mathrm{H}_{2} \mathrm{O}$ before by Suárez et al. (2007), but at that time 

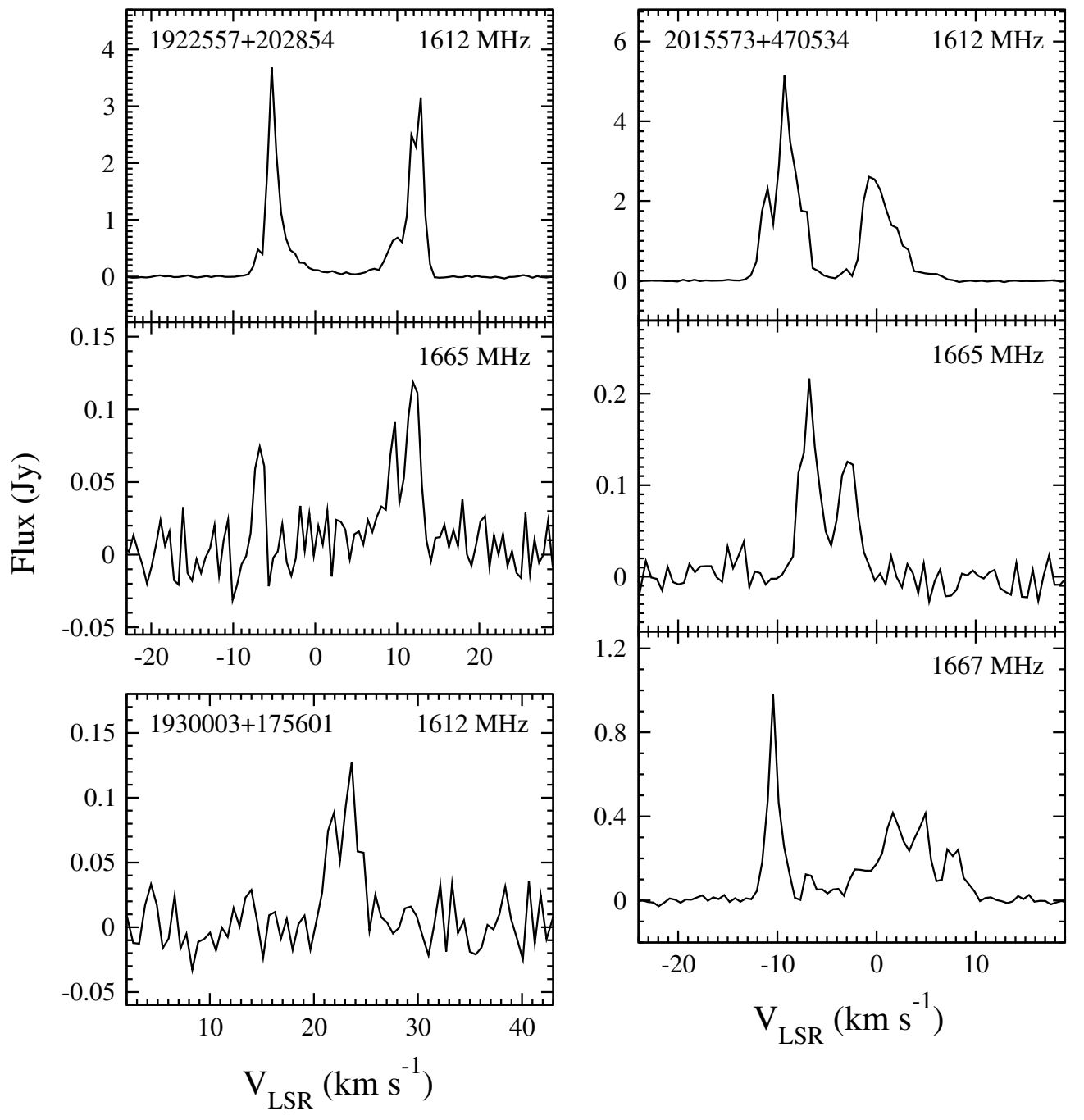

Figure 1. (Continued)

the result was a non-detection (corresponding rms $\sim 0.04 \mathrm{Jy}$ ). Therefore, the maser emission could be at a minimum during their observing period, while another possibility is that the maser appeared after 2007. The systemic velocity of this object is about $-105 \mathrm{~km} \mathrm{~s}^{-1}$ according to the maser spectra. The kinematic distance derived using the systemic velocity and the Galactic rotation curve (Kothes \& Dougherty 2007) is about $30 \mathrm{kpc}$. This puts the object outside the Milky Way, which is unlikely true. The total infrared flux estimated from its SED is about $2.3 \times 10^{-12} \mathrm{~W} \mathrm{~m}^{-2}$. Assuming a luminosity of $10,000 L_{\odot}$ (quite typical for a post-AGB star), the resultant luminosity distance is about $12 \mathrm{kpc}$, but this distance also includes a large uncertainty.

\subsubsection{Objects with High-velocity OH Maser Emission}

1807272-194639. The $\mathrm{OH} 1612 \mathrm{MHz}$ spectrum shows four emission peaks (at about $-77 \mathrm{~km} \mathrm{~s}^{-1},-48 \mathrm{~km} \mathrm{~s}^{-1}, 4 \mathrm{~km} \mathrm{~s}^{-1}$, and $30 \mathrm{~km} \mathrm{~s}^{-1}$ ) with a maximum velocity coverage of $\sim 107 \mathrm{~km} \mathrm{~s}^{-1}$ (Figure 1). A "U-shaped" double-peaked profile is found in the $1667 \mathrm{MHz}$ spectrum, which is a signature of a spherically expanding envelope commonly associated with AGB stars (e.g., te Lintel Hekkert et al. 1989). The velocities of the two $1667 \mathrm{MHz}$ peaks match with two of the $1612 \mathrm{MHz}$ peaks at
-77 and $-48 \mathrm{~km} \mathrm{~s}^{-1}$. Therefore, these lines probably originate from the same object with systemic velocity $\sim 63 \mathrm{~km} \mathrm{~s}^{-1}$. The peaks at 4 and $30 \mathrm{~km} \mathrm{~s}^{-1}$ could be the result of a high-velocity jet, but they could also arise from another object with a different systemic velocity, because the $\mathrm{OH}$ beam covers seven more midinfrared sources. The angular separations between those sources and our target are about 100"-220". In particular, the [09]-[18] colors of three of them are between 0 and 1, indicating that they could be AGB stars (Paper I). Flux data for longer wavelengths are not available, and no other information could be found for these three objects. There is also an absorption feature found at about $-30 \mathrm{~km} \mathrm{~s}^{-1}$, but it is not clear how this is related to the $1612 \mathrm{MHz}$ emission. There is no $\mathrm{H}_{2} \mathrm{O}$ maser detection.

IRAS 18251-1048. This is a known OH (1612 and $1667 \mathrm{MHz}$; Engels \& Jimenez-Esteban 2007) and $\mathrm{H}_{2} \mathrm{O}$ (Engels et al. 1986) maser source. It is characterized by a relatively wide velocity coverage $\left(\sim 44 \mathrm{~km} \mathrm{~s}^{-1}\right)$ of its $\mathrm{OH} 1612 \mathrm{MHz}$ emission (Figure 1). The expansion velocity of the envelope, usually taken as half of the $\mathrm{OH}$ velocity coverage, is about $22 \mathrm{~km} \mathrm{~s}^{-1}$. This is amongst the largest expansion velocities for typical oxygen-rich AGB stars (te Lintel Hekkert et al. 1989). In this observation, a new $1667 \mathrm{MHz}$ emission peak was detected at about $30 \mathrm{~km} \mathrm{~s}^{-1}$, and the corresponding velocity coverage becomes $\sim 135 \mathrm{~km} \mathrm{~s}^{-1}$. Nonetheless, we cannot rule out the possibility of contamination 

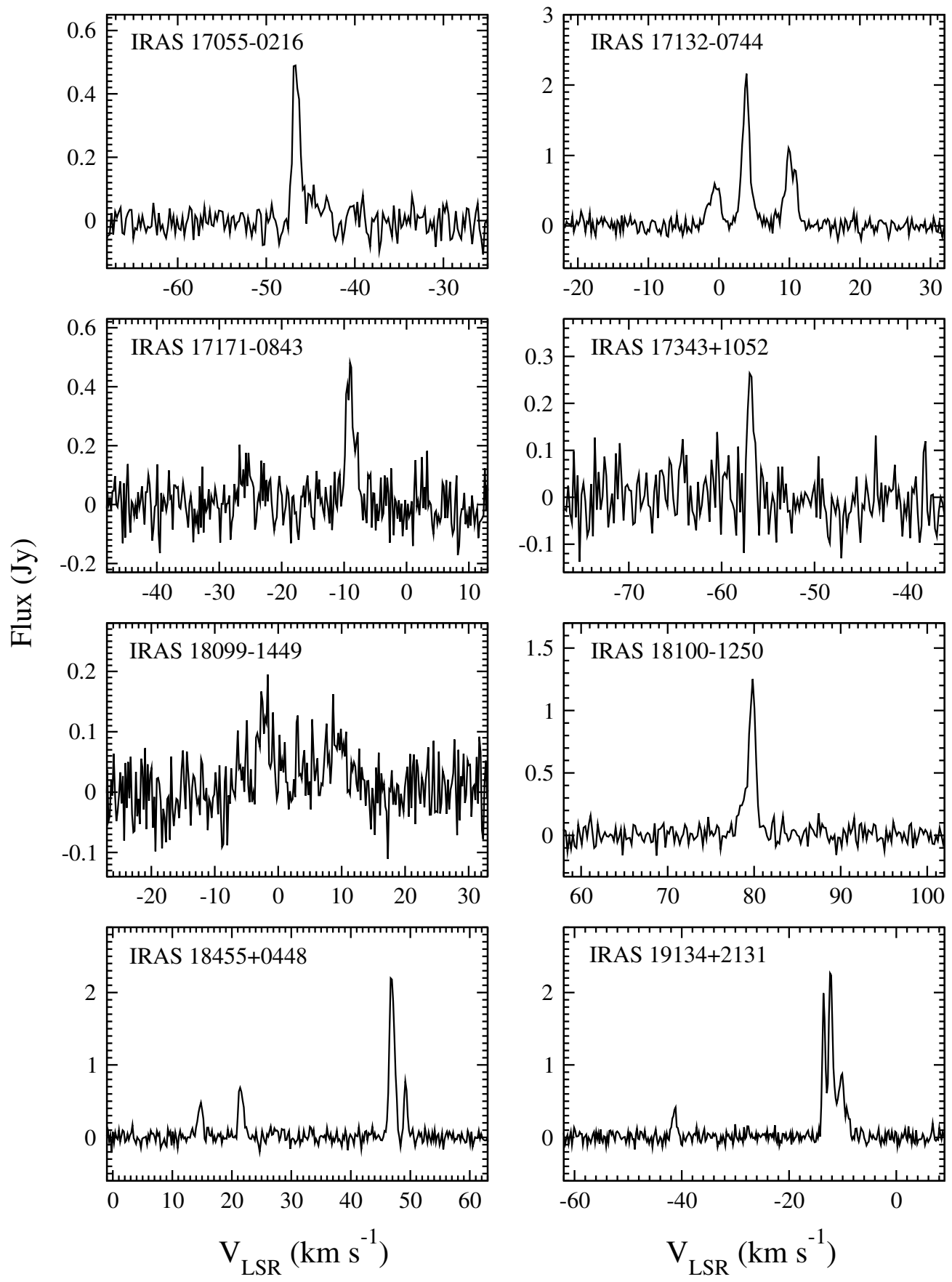

Figure 2. Spectra of objects with $\mathrm{H}_{2} \mathrm{O}$ maser detections only.

because there is another infrared source in the vicinity $\left(\sim 2^{\prime}\right)$ of this object. The color of this object is not known because a lot of band fluxes are missing, probably because it is very dim. The absorption feature at $6 \mathrm{~km} \mathrm{~s}^{-1}$ looks suspicious as it is not usually seen in evolved stars. It might again be explained by the presence of some foreground molecular gas, or undesired emissions in the OFF-positions.

$1904448+042318$ (or SSTGLMC G038.3546-00.9519). The $\mathrm{OH} 1612 \mathrm{MHz}$ spectrum consists of two dominant peaks and multiple weaker peaks (Figure 1). The total velocity coverage is $\sim 77 \mathrm{~km} \mathrm{~s}^{-1}$, much larger than that of usual AGB stars. The 1665 and $1667 \mathrm{MHz}$ spectra reveal a similar coverage, but instead of a dominant double peak, they exhibit a relatively irregular profile. There is another infrared source 1.5 apart from this object, with color [09] $-[18]=0.42$ (i.e., AGB candidate; note that flux data for longer wavelengths are not available). However, in this case we suggest that all the $\mathrm{OH}$ emission is more likely arising from the same object, due to the fact that all three $\mathrm{OH}$ lines show roughly the same velocity distribution (from about 11 to $90 \mathrm{~km} \mathrm{~s}^{-1}$ ), indicating the same systemic velocity at about $50 \mathrm{~km} \mathrm{~s}^{-1}$. It is not so likely to have two different objects producing the three similar velocity coverages, unless they both have the same systemic velocity and shell expansion velocity. If all the emission peaks originated from the same object, then there is probably a high-velocity jet that produces the large velocity coverage. The three $\mathrm{OH}$ line shapes look different because in the case of a jet, the maser excitation would be mainly caused by the jet-envelope collision, which 

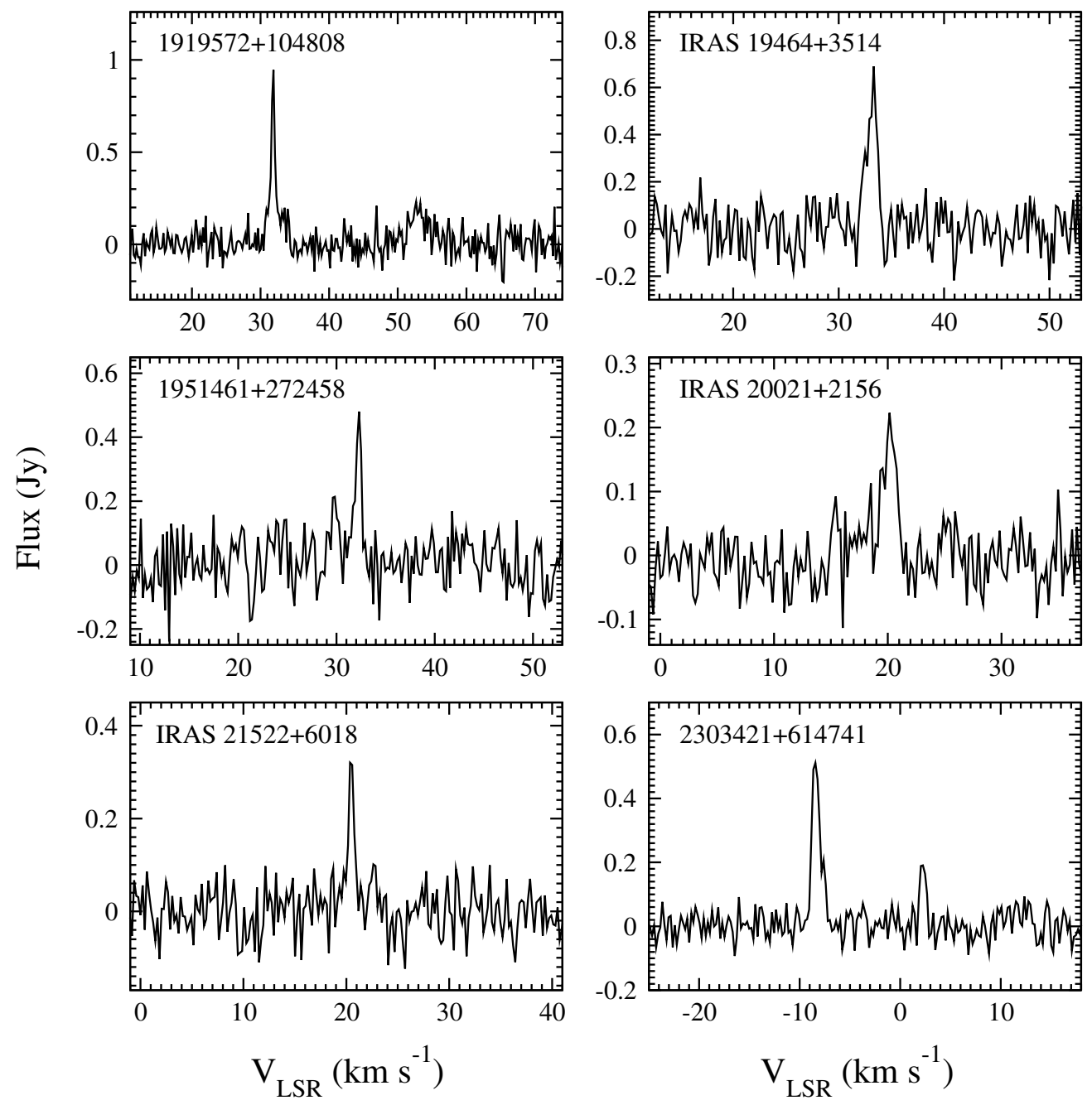

Figure 2. (Continued)

produces irregular line features (e.g., Zijlstra et al. 2001). There is a suspicious absorption feature at $20 \mathrm{~km} \mathrm{~s}^{-1}$ with unknown origin. $\mathrm{No}_{2} \mathrm{O}$ maser is detected.

IRAS 19027+0517. There is one emission peak at about $14 \mathrm{~km} \mathrm{~s}^{-1}$ and one absorption feature at $82 \mathrm{~km} \mathrm{~s}^{-1}$ in the $\mathrm{OH} 1612 \mathrm{MHz}$ spectrum. The 1665 and $1667 \mathrm{MHz}$ spectra have multiple peaks spreading from $14 \mathrm{~km} \mathrm{~s}^{-1}$ to $86 \mathrm{~km} \mathrm{~s}^{-1}$ (Figure 1). The resulting velocity coverage is about $72 \mathrm{~km} \mathrm{~s}^{-1}$, which looks like another candidate with high-velocity outflow. There is no $\mathrm{H}_{2} \mathrm{O}$ maser detection.

\subsubsection{Peculiar Detections/Non-detections}

IRAS 18587+0521. This is a new $\mathrm{OH}$ and $\mathrm{H}_{2} \mathrm{O}$ maser source, but the spectra may originate from two objects (Figure 3). There are two infrared sources (IRAS 18587+0521A and IRAS $18587+0521 \mathrm{~B})$ with $1^{\prime}$ separation under the same IRAS assignment. IRAS 18587+0521A falls into the "post-AGB star" color region of the aforementioned $A K A R I$ two-color diagram. There are no $65 \mu \mathrm{m}$ data for IRAS $18587+0521 \mathrm{~B}$ and thus its position on the diagram is unknown, but it has a bluer [09]-[18] color than its neighbor. The $\mathrm{H}_{2} \mathrm{O}$ beam was small enough to resolve the two sources, so the $\mathrm{H}_{2} \mathrm{O}$ maser has been confirmed to be arising from IRAS $18587+0521 \mathrm{~B}$. On the contrary, there was no way to determine the origin of the $\mathrm{OH}$ maser. Therefore, even though there is an $\mathrm{H}_{2} \mathrm{O}$ peak outside the $\mathrm{OH} 1612 \mathrm{MHz}$ cover- age (i.e., WF characteristic), we do not have enough confidence to claim that it is a WF candidate. The $\mathrm{OH}$ spectra of this source also suffered from severe contamination by absorption features of unknown origin.

IRAS 18056-1514. This object was suggested to be a lowvelocity WF after we have identified an $\mathrm{H}_{2} \mathrm{O}$ maser peak with $0.5 \mathrm{Jy}$ peak flux at $36 \mathrm{~km} \mathrm{~s}^{-1}$, outside its $\mathrm{OH}$ maser coverage (Paper I). That peak disappeared in the current observation with comparable rms noise level (30 mJy in Paper I and $50 \mathrm{mJy}$ here). Without that peak, the current spectrum looks similar to a usual AGB star (Figure 3). The peak disappeared probably due to the commonly observed flux variations of $22 \mathrm{GHz} \mathrm{H}_{2} \mathrm{O}$ masers, which typically occur on timescales of months.

IRAS 19312+1950. The true nature of this object is still uncertain, but it could be a post-AGB star embedded in a small dark cloud (see Nakashima et al. 2011 for a detailed study of this object). The object used to have two stable $\mathrm{H}_{2} \mathrm{O}$ maser peaks at about 17 and $48 \mathrm{~km} \mathrm{~s}^{-1}$, which correspond to the two tips of its bipolar flow. An additional peak was detected at $26 \mathrm{~km} \mathrm{~s}^{-1}$ in our previous survey (Paper I). In the present observation, we find that only the most blueshifted peak at $17 \mathrm{~km} \mathrm{~s}^{-1}$ is still visible (Figure 3 ). As the rms noise level of the current work is similar to that in Paper I (60 mJy in Paper I and $70 \mathrm{mJy}$ here), the sudden disappearance of the other two emission peaks are likely due to flux variations of the $\mathrm{H}_{2} \mathrm{O}$ maser. However, it might 

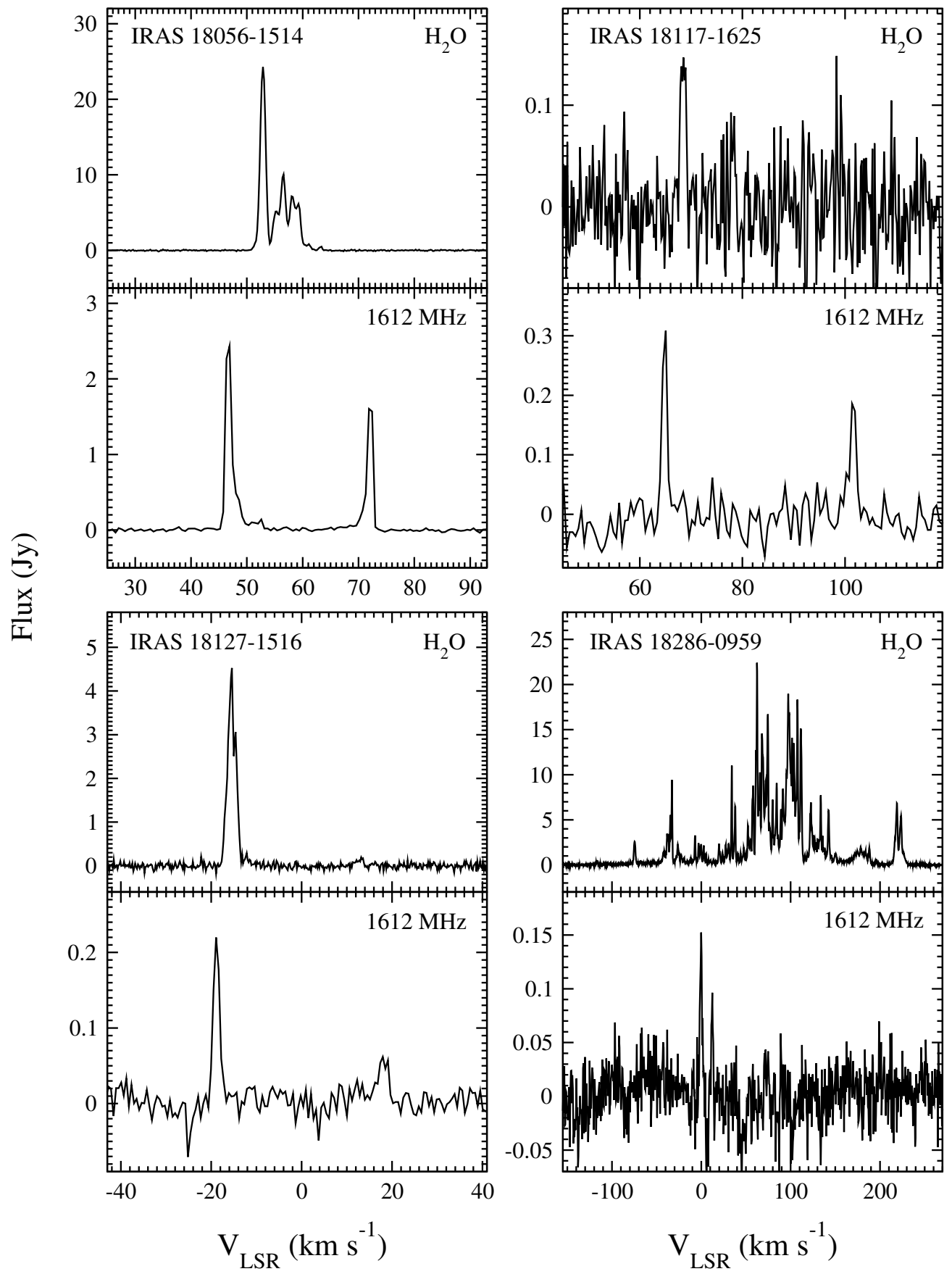

Figure 3. Spectra of objects with both $\mathrm{OH}$ and $\mathrm{H}_{2} \mathrm{O}$ maser detections.

also hint at a possible change in the physical condition of the envelope.

\section{DISCUSSION}

In this section, the $Q$-parameters and AKARI colors of the observed maser sources are discussed. By adding these infrared properties, we suggest an improved way to identify the evolutionary status of evolved stars, especially for those at the late AGB/post-AGB phase.

\subsection{The $Q 1$ and $Q 2$ Parameters}

The $Q 1$ and $Q 2$ parameters were introduced by Negueruela \& Schurch (2007) and Messineo et al. (2012). They are defined as

$$
\begin{aligned}
& Q 1=(J-H)-1.8 \times\left(H-K_{\mathrm{s}}\right), \\
& Q 2=\left(J-K_{\mathrm{s}}\right)-2.69 \times\left(K_{\mathrm{s}}-[8.0]\right),
\end{aligned}
$$

where $J(1.25 \mu \mathrm{m}), H(1.65 \mu \mathrm{m})$, and $K_{\mathrm{s}}(2.17 \mu \mathrm{m})$ represent the three band fluxes of the Two Micron All Sky Survey (2MASS; Skrutskie et al. 2006), and [8.0] is the $8 \mu \mathrm{m}$ band flux from the Galactic Legacy Infrared Mid-Plane Survey Extraordinaire (GLIMPSE; Benjamin et al. 2003; Churchwell et al. 2009). The $Q 1$ parameter was originally used to select infrared counterparts of high-mass X-ray binaries, and it was also useful in finding red 

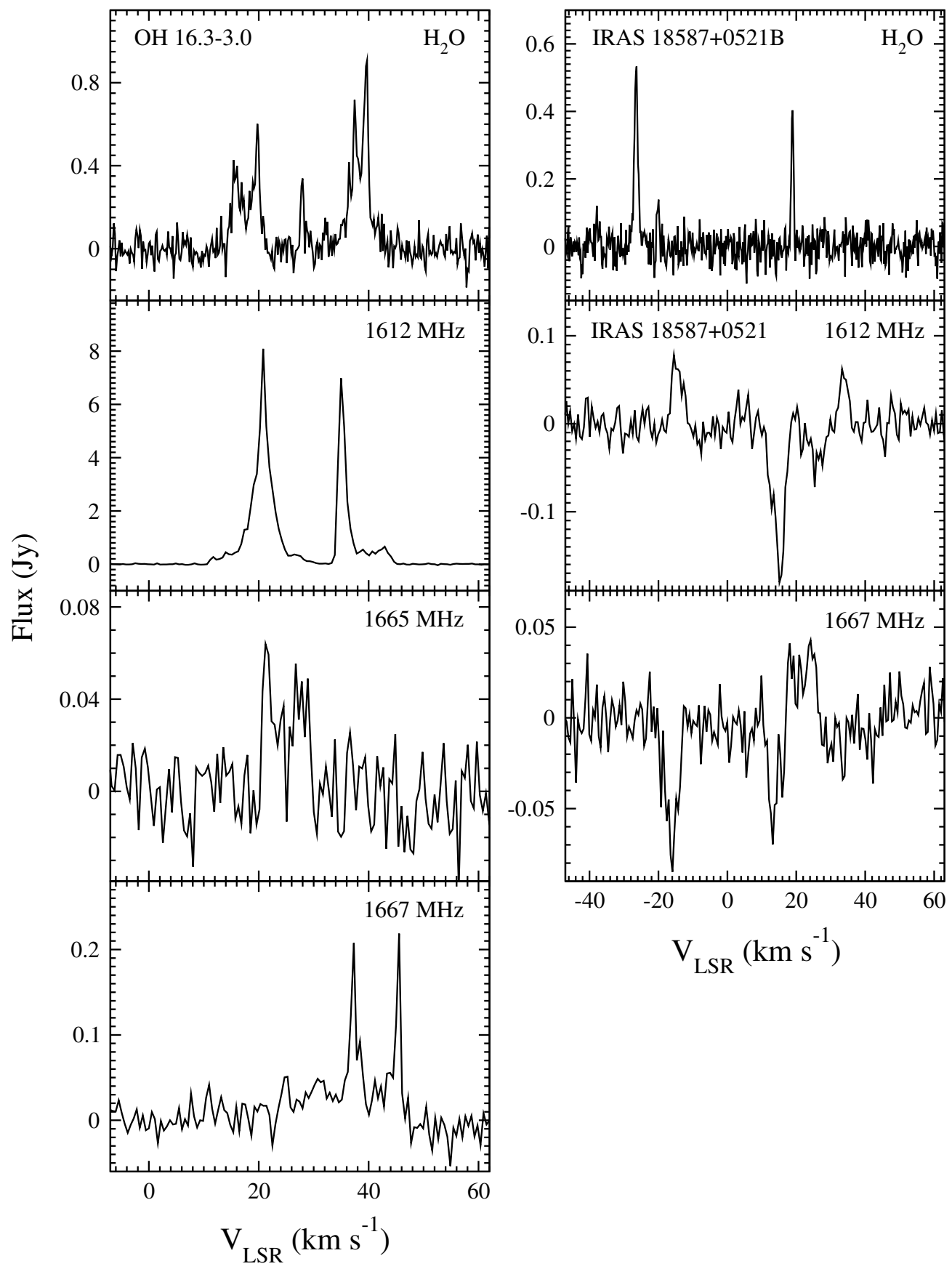

Figure 3. (Continued)

supergiant clusters (Negueruela \& Schurch 2007; Negueruela et al. 2011; Fok et al. 2012). The $Q 2$ parameter was inspired by $Q 1$, but in addition to the near-infrared 2MASS data, the midinfrared [8.0] data were also included. This parameter could be used to measure the infrared excess due to circumstellar shells only, which is independent of interstellar extinction (Messineo et al. 2012). Therefore, comparing to $Q 1, Q 2$ is more sensitive to the nature of circumstellar envelopes of evolved stars. In Messineo et al. (2012), the [8.0] entries were preferably taken from the GLIMPSE database, because it has a high resolution $\left(\sim 1^{\prime \prime}\right.$.2). However, since the GLIMPSE project mainly covered the region within Galactic latitudes $b= \pm 1^{\circ}$ along most part of the Galactic plane, many of our objects are therefore not included because evolved stars tend to drift away from the
Galactic plane. Thus, we have used the $A(8.28 \mu \mathrm{m})$ band data from the MSX (Egan et al. 2003) instead of GLIMPSE. It was shown that this change would not alter the behavior of the $Q 2$ parameter (see Figure 4 in Messineo et al. 2012). Since $Q 1$ and $Q 2$ serve like colors (but free from the effect of interstellar extinction) that are affected by the profile of the spectral energy distributions (SEDs), it is expected that most of the objects at the same stage of stellar evolution will share the same ranges of $Q$ values. Hence, they will cluster in the $Q 1-Q 2$ diagram, similar to the cases of two-color diagrams (see, e.g., IRAS two-color diagram; van der Veen \& Habing 1988). Figure 4 shows the $Q 1-Q 2$ diagram of the observed targets in this project, together with the $\mathrm{H}_{2} \mathrm{O}$ sources detected in Paper I. The objects are found within $-7<Q 1<2$ and $-37<Q 2<0$, but most of them 

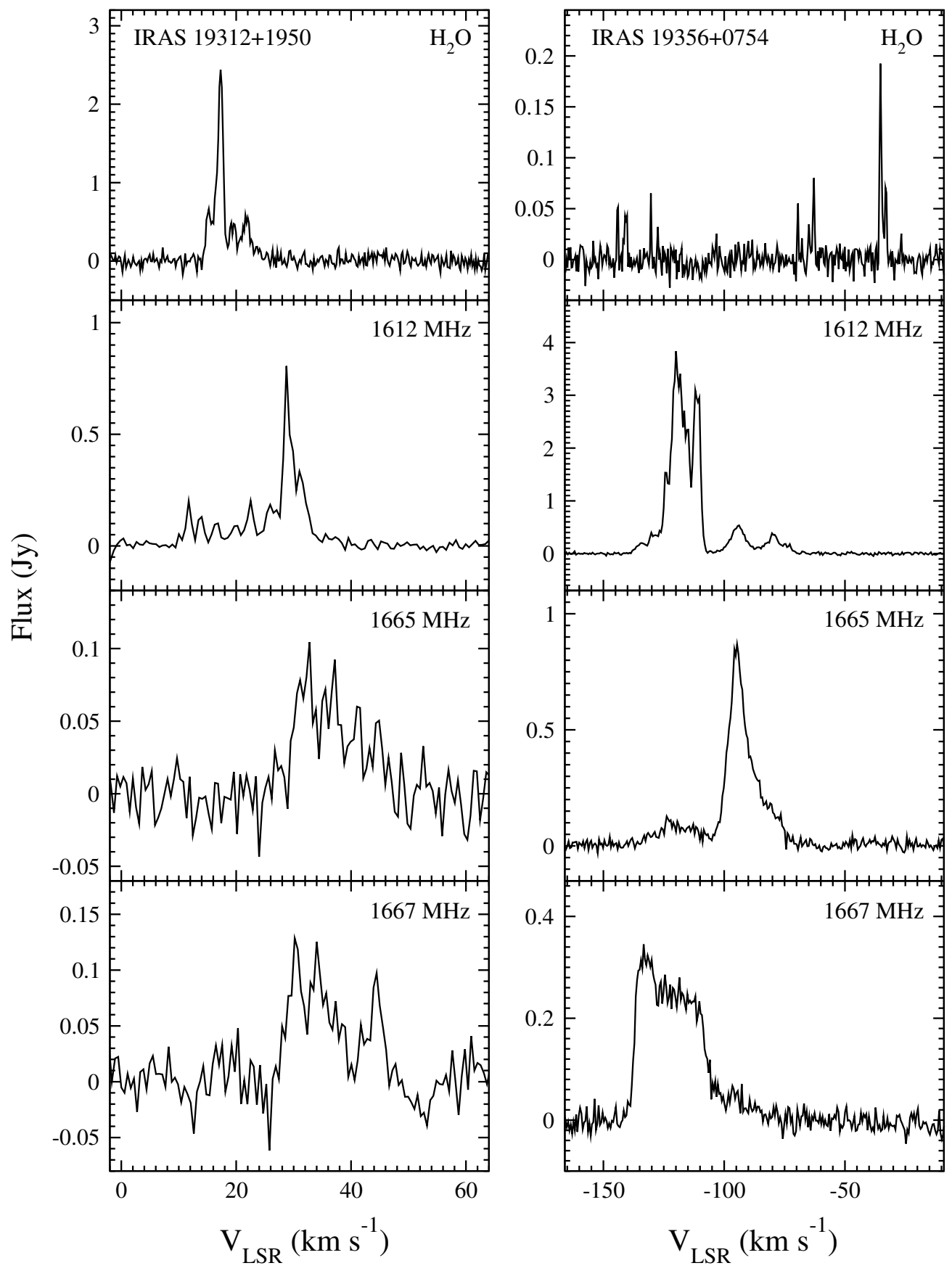

Figure 3. (Continued)

are distributed roughly in the cluster with $-2<Q 1<1$ and $-15<Q 2<0$. Some objects extend from this main cluster toward the negative $Q 2$ direction, while some others are found in another region with more negative $Q 1$ values. The range of $Q 2$ values occupied by our maser sources is larger when compared to the range of $Q 1$ values, which means the objects have a wider range of flux values in the mid- or far- infrared regions (reflected by $Q 2$ ) than in the near-infrared region (reflected by $Q 1)$.

Before any further discussion, we have to consider the possible influence of artificial effects or contamination. The interstellar extinction has been a big problem for infrared research, and the situation becomes even more severe for the region toward the Galactic plane. In fact, the $Q 2$ parameter was designed in a way to avoid the effect of extinction. Figure 5 shows a diagram of $Q 2$ versus Galactic $b$. We can see that there are more $\mathrm{OH}$ maser sources in the region with $|b|<1^{\circ}$. However, the $Q 2$ values of our $\mathrm{OH}$ and $\mathrm{H}_{2} \mathrm{O}$ maser sources do not have a clear correlation with Galactic latitude. Hence, even if there is a positional dependence for the $Q 2$ value, it is not significant. Another possible source of error comes from the resolution of the $\mathrm{OH}$ maser observations. Since the large beam occasionally covered more than one source with similar infrared characteristics, sometimes it is a bit difficult to confirm which source the $\mathrm{OH}$ maser comes from. This would not be a problem for the sources where $\mathrm{H}_{2} \mathrm{O}$ masers were detected as well, because in those cases the origin of the $\mathrm{OH}$ masers could be checked by comparing the line velocities of 


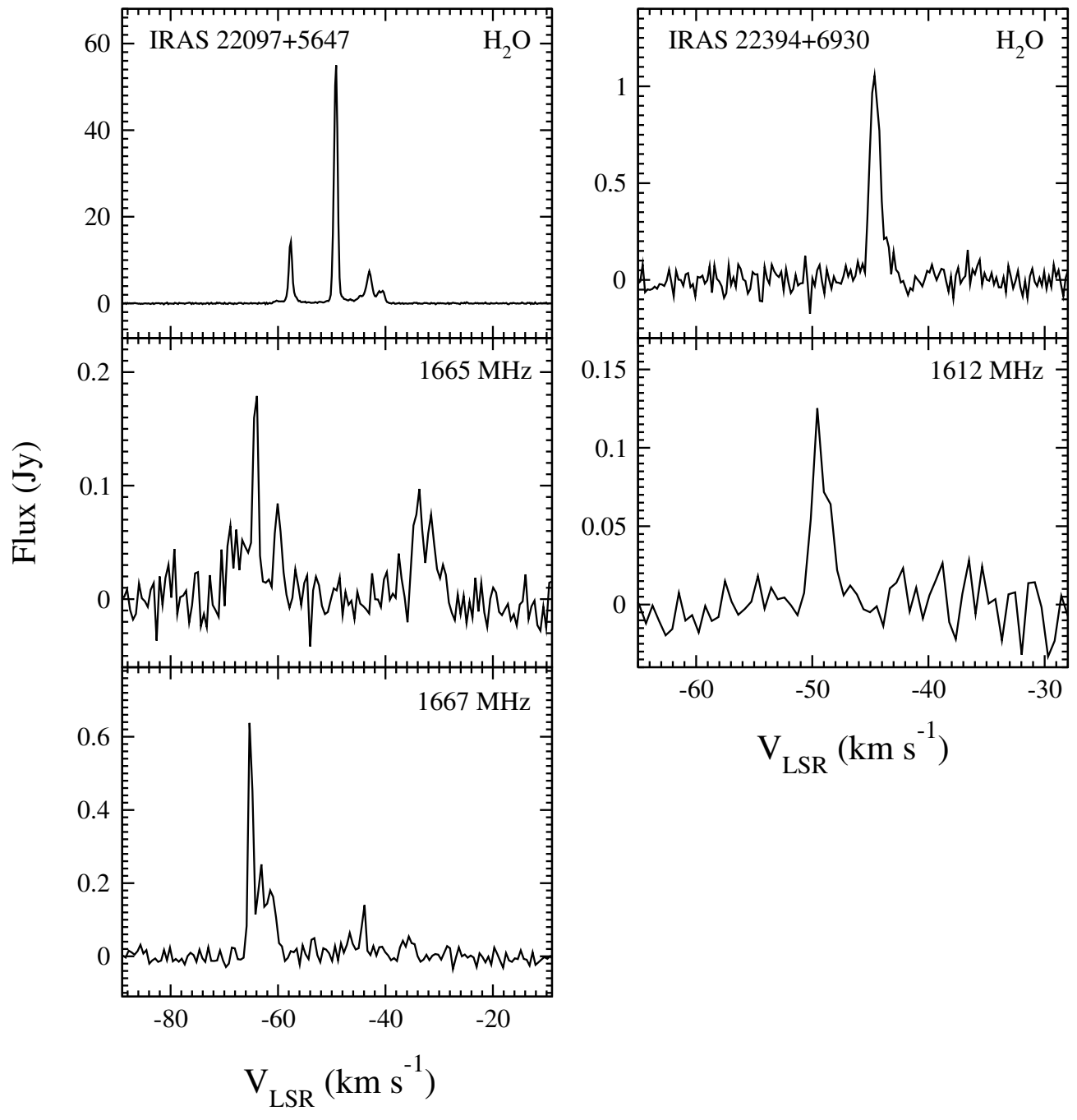

Figure 3. (Continued)

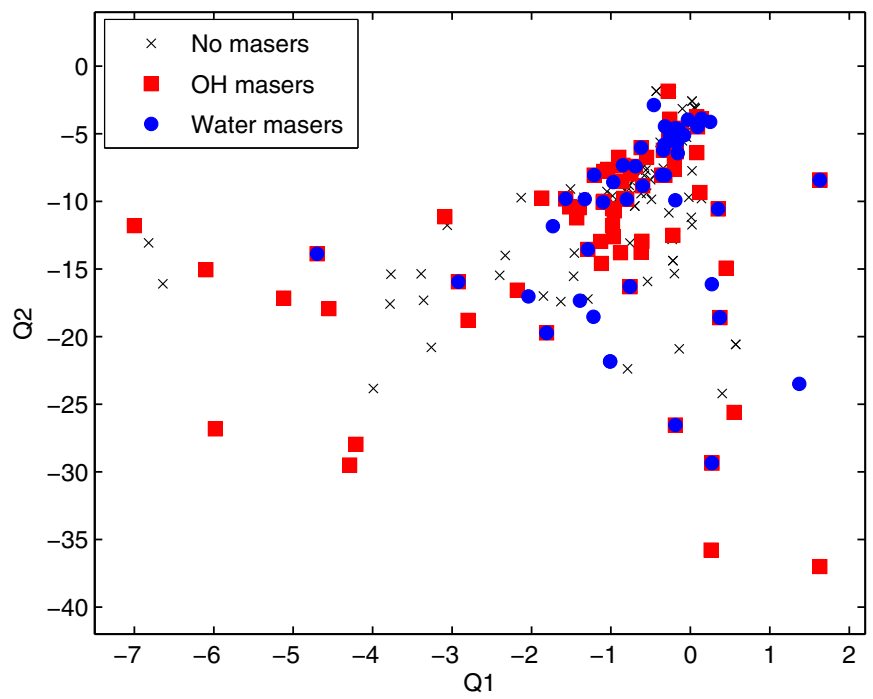

Figure 4. $Q 1-Q 2$ diagram of the objects observed in the current project. The $\mathrm{OH}$ and $\mathrm{H}_{2} \mathrm{O}$ sources are specified by the filled red squares and filled blue circles, respectively. The $\mathrm{H}_{2} \mathrm{O}$ detections in Paper I are also included. Many of them are AGB stars. The non-detections are specified by the black crosses.

(A color version of this figure is available in the online journal.) both masers. The ambiguous cases are discussed in Section 3.2 already.

Figure 6 shows basically the same $Q 1-Q 2$ diagram as Figure 4, but with the addition of a number of known sources for a comparison. The PPNe were obtained from Meixner et al. (1999). The PNe were mainly selected from Ruffle et al. (2004) and the ARVAL Catalogue of Bright Planetary Nebulae. ${ }^{7}$ The objects form three groups in the diagram that are more or less similar to Figure 4. The group enclosed by a blue ellipse is dominated by AGB $\mathrm{H}_{2} \mathrm{O}$ maser sources from Paper I. Many of them are still keeping a rather spherical envelope, as suggested by their spectral profiles. They have an elongated distribution pattern that roughly extends along the blackbody curve. The group enclosed by a purple ellipse is dominated by WFs and PPNe, which are mostly bipolar objects. These objects are expected to be more evolved than the spherical objects, based on the assumption that jets usually develop at a later stage of evolution (but recall there are exceptions such as X Her and V Hya, which are AGB stars with bipolar structure; see Section 1). Since they probably have thicker and more extended envelopes, the temperature is lower and hence the more negative $Q 2$ values (about -10 to -40 ). The position of the new WF candidate,

\footnotetext{
7 http://www.oarval.org/PNeb.htm
} 
Table 2

Parameters of the $\mathrm{OH}$ Maser Detections

\begin{tabular}{|c|c|c|c|c|c|c|c|c|c|c|c|}
\hline Object & $\begin{array}{l}\text { Rest Freq. } \\
(\mathrm{MHz})\end{array}$ & $\begin{array}{c}V_{\mathrm{b}, \mathrm{p}}^{\mathrm{a}} \\
\left(\mathrm{km} \mathrm{s}^{-1}\right)\end{array}$ & $\begin{array}{c}F_{\mathrm{b}, \mathrm{p}}^{\mathrm{a}} \\
(\mathrm{Jy})\end{array}$ & $\begin{array}{c}V_{\mathrm{r}, \mathrm{p}}^{\mathrm{b}} \\
\left(\mathrm{km} \mathrm{s}^{-1}\right)\end{array}$ & $\begin{array}{l}F_{\mathrm{r}, \mathrm{p}}{ }^{\mathrm{b}} \\
(\mathrm{Jy})\end{array}$ & $\begin{array}{c}V_{\mathrm{b}, \mathrm{e}^{\mathrm{c}}} \\
\left(\mathrm{km} \mathrm{s}^{-1}\right)\end{array}$ & $\begin{array}{c}V_{\mathrm{r}, \mathrm{e}}^{\mathrm{c}} \\
\left(\mathrm{km} \mathrm{s}^{-1}\right)\end{array}$ & $\begin{array}{c}I^{\mathrm{d}} \\
\left(\mathrm{Jy} \mathrm{km} \mathrm{s}^{-1}\right)\end{array}$ & $\begin{array}{l}\mathrm{rms} \\
(\mathrm{Jy})\end{array}$ & Ref. $^{e}$ & $\begin{array}{c}\text { Absorptions }^{\mathrm{f}} \\
\left(\mathrm{km} \mathrm{s}^{-1}\right)\end{array}$ \\
\hline \multirow[t]{3}{*}{$1807272-194639$} & 1612 & -48.4 & 0.62 & $\ldots$ & $\ldots$ & -77.4 & 30.4 & 2.71 & 0.03 & New & $\ldots$ \\
\hline & 1665 & $\ldots$ & $\ldots$ & $\ldots$ & $\ldots$ & $\ldots$ & $\ldots$ & $\ldots$ & 0.03 & $\ldots$ & 32.2 \\
\hline & 1667 & -76.3 & 0.88 & -45.5 & 0.28 & -77.9 & -43.3 & 2.69 & 0.03 & 1 & 26.9 \\
\hline \multirow[t]{3}{*}{ IRAS $18056-1514$} & 1612 & 46.9 & 2.44 & 71.9 & 1.60 & 45.2 & 73.0 & 6.84 & 0.02 & 2 & $\ldots$ \\
\hline & 1665 & $\ldots$ & $\ldots$ & $\ldots$ & $\ldots$ & $\ldots$ & $\ldots$ & $\ldots$ & 0.02 & $\ldots$ & $\ldots$ \\
\hline & 1667 & $\ldots$ & $\ldots$ & $\ldots$ & $\ldots$ & $\ldots$ & $\ldots$ & $\ldots$ & 0.01 & $\ldots$ & $\ldots$ \\
\hline \multirow[t]{3}{*}{ IRAS $18117-1625$} & 1612 & 65.1 & 0.31 & 101.4 & 0.19 & 63.9 & 102.5 & 0.55 & 0.03 & New & $\ldots$ \\
\hline & 1665 & $\ldots$ & $\ldots$ & $\ldots$ & $\ldots$ & $\ldots$ & $\ldots$ & $\ldots$ & 0.02 & $\ldots$ & $\ldots$ \\
\hline & 1667 & $\ldots$ & $\ldots$ & $\ldots$ & $\ldots$ & $\ldots$ & $\ldots$ & $\ldots$ & 0.03 & $\ldots$ & $\ldots$ \\
\hline \multirow[t]{3}{*}{ IRAS 18118-1615 } & 1612 & 162.7 & 0.24 & $\ldots$ & $\ldots$ & 161.5 & 163.8 & 0.24 & 0.02 & New & $\ldots$ \\
\hline & 1665 & $\ldots$ & $\ldots$ & $\ldots$ & $\ldots$ & $\ldots$ & $\ldots$ & $\ldots$ & 0.02 & $\ldots$ & $\ldots$ \\
\hline & 1667 & 170.1 & 0.09 & $\ldots$ & $\ldots$ & 160.0 & 178.0 & 0.42 & 0.02 & New & $\ldots$ \\
\hline \multirow[t]{3}{*}{ IRAS $18127-1516$} & 1612 & -18.9 & 0.22 & 18.0 & 0.06 & -20.1 & 20.0 & 0.71 & 0.01 & New & $\ldots$ \\
\hline & 1665 & $\ldots$ & $\ldots$ & $\ldots$ & $\ldots$ & $\ldots$ & $\ldots$ & $\ldots$ & 0.01 & $\ldots$ & $\ldots$ \\
\hline & 1667 & $\ldots$ & $\ldots$ & $\ldots$ & $\ldots$ & $\ldots$ & $\ldots$ & $\ldots$ & 0.01 & $\ldots$ & $\ldots$ \\
\hline \multirow[t]{3}{*}{$1824037+063625$} & 1612 & $\ldots$ & $\ldots$ & $\ldots$ & $\ldots$ & $\ldots$ & $\ldots$ & $\ldots$ & 0.01 & $\ldots$ & $\ldots$ \\
\hline & 1665 & $\ldots$ & $\ldots$ & $\ldots$ & $\ldots$ & $\ldots$ & $\ldots$ & $\ldots$ & 0.01 & $\ldots$ & $\ldots$ \\
\hline & 1667 & -29.1 & 0.11 & -10.4 & 0.12 & -30.1 & -9.9 & 0.28 & 0.02 & New & $\ldots$ \\
\hline \multirow[t]{3}{*}{ IRAS $18251-1048$} & 1612 & 71.3 & 1.49 & 111.0 & 2.17 & 67.9 & 112.2 & 10.55 & 0.03 & 3 & 81.5 \\
\hline & 1665 & $\ldots$ & $\ldots$ & $\ldots$ & $\ldots$ & $\ldots$ & $\ldots$ & $\ldots$ & 0.04 & $\ldots$ & $\ldots$ \\
\hline & 1667 & 23.0 & 0.14 & 113.0 & 0.17 & 9.3 & 126.2 & 3.87 & 0.03 & 3 & 7.1 \\
\hline \multirow[t]{3}{*}{ IRAS $18286-0959$} & 1612 & -0.2 & 0.15 & 12.3 & 0.10 & -2.5 & 14.0 & 0.50 & 0.02 & 4 & $\ldots$ \\
\hline & 1665 & $\ldots$ & $\ldots$ & $\ldots$ & $\ldots$ & $\ldots$ & $\ldots$ & $\ldots$ & 0.02 & $\ldots$ & 4.2 \\
\hline & 1667 & $\ldots$ & $\ldots$ & $\ldots$ & $\ldots$ & $\ldots$ & $\ldots$ & $\ldots$ & 0.02 & $\ldots$ & 6.0 \\
\hline \multirow[t]{3}{*}{ OH $16.3-3.0$} & 1612 & 20.8 & 8.09 & 35.0 & 6.98 & 11.2 & 45.2 & 41.37 & 0.02 & 4 & $\ldots$ \\
\hline & 1665 & 21.2 & 0.06 & $\ldots$ & $\ldots$ & 20.1 & 30.0 & 0.31 & 0.01 & New & $\ldots$ \\
\hline & 1667 & 45.5 & 0.22 & $\ldots$ & $\ldots$ & 24.7 & 46.6 & 1.05 & 0.01 & New & $\ldots$ \\
\hline \multirow[t]{3}{*}{$1838595-052024$} & 1612 & 41.2 & 0.13 & $\ldots$ & $\ldots$ & 40.1 & 44.1 & 0.23 & 0.02 & New & $67.3,102.5$ \\
\hline & 1665 & $\ldots$ & $\ldots$ & $\ldots$ & $\ldots$ & $\ldots$ & $\ldots$ & $\ldots$ & 0.02 & $\ldots$ & $\ldots$ \\
\hline & 1667 & 21.4 & 0.07 & $\ldots$ & $\ldots$ & 17.6 & 59.8 & 0.75 & 0.02 & New & $\ldots$ \\
\hline \multirow[t]{3}{*}{$1854158+011501$} & 1612 & 19.1 & 0.41 & 45.8 & 0.86 & 18.0 & 46.9 & 2.85 & 0.02 & New & $\ldots$ \\
\hline & 1665 & 36.6 & 0.07 & $\ldots$ & $\ldots$ & 33.9 & 40.5 & 0.33 & 0.02 & New & $\ldots$ \\
\hline & 1667 & 37.3 & 0.13 & $\ldots$ & $\ldots$ & 32.9 & 41.1 & 0.69 & 0.02 & New & $12.6,29.1,55.4$ \\
\hline $1854250+004958$ & 1612 & 12.3 & 0.14 & $\ldots$ & $\ldots$ & 8.9 & 13.4 & 0.33 & 0.02 & New & $\ldots$ \\
\hline & 1665 & $\ldots$ & $\ldots$ & $\ldots$ & $\ldots$ & $\ldots$ & $\ldots$ & $\ldots$ & 0.02 & $\ldots$ & 21.8 \\
\hline & 1667 & $\ldots$ & $\ldots$ & $\ldots$ & $\ldots$ & $\ldots$ & $\ldots$ & $\ldots$ & 0.02 & $\ldots$ & 13.1 \\
\hline IRAS $18587+0521$ & 1612 & -15.5 & 0.08 & 33.9 & 0.05 & -17.2 & 35.6 & -0.58 & 0.01 & New & $\ldots$ \\
\hline & 1665 & $\ldots$ & $\ldots$ & $\ldots$ & $\ldots$ & $\ldots$ & $\ldots$ & $\ldots$ & 0.01 & $\ldots$ & $-14.5,14.6$ \\
\hline & 1667 & 24.1 & 0.04 & $\ldots$ & $\ldots$ & 20.8 & 25.8 & 0.16 & 0.01 & New & $\ldots$ \\
\hline $1904448+042318$ & 1612 & 15.7 & 0.13 & 76.4 & 0.32 & 12.3 & 88.9 & 2.27 & 0.02 & New & 20.8 \\
\hline & 1665 & 63.5 & 0.20 & $\ldots$ & $\ldots$ & 16.8 & 91.0 & 1.51 & 0.02 & New & 20.1 \\
\hline & 1667 & 17.0 & 0.41 & $\ldots$ & $\ldots$ & 12.6 & 91.1 & 2.83 & 0.02 & New & $\ldots$ \\
\hline IRAS $19027+0517$ & 1612 & 13.4 & 0.15 & $\ldots$ & $\ldots$ & 11.2 & 18.0 & 0.44 & 0.02 & New & 82.1 \\
\hline & 1665 & 32.8 & 0.05 & 77.3 & 0.10 & 28.9 & 85.0 & 1.32 & 0.02 & New & $\ldots$ \\
\hline & 1667 & 78.4 & 0.14 & $\ldots$ & $\ldots$ & 12.6 & 86.7 & 1.86 & 0.02 & New & $\ldots$ \\
\hline IRAS 19074+0534 & 1612 & 12.3 & 0.06 & $\ldots$ & $\ldots$ & 11.1 & 13.4 & 0.07 & 0.01 & New & $\ldots$ \\
\hline & 1665 & $\ldots$ & $\ldots$ & $\ldots$ & $\ldots$ & $\ldots$ & $\ldots$ & $\ldots$ & 0.01 & $\ldots$ & 78.3 \\
\hline & 1667 & $\ldots$ & $\ldots$ & $\ldots$ & $\ldots$ & $\ldots$ & $\ldots$ & $\ldots$ & 0.01 & $\ldots$ & 76.3 \\
\hline $1914408+114449$ & 1612 & $\ldots$ & $\ldots$ & $\ldots$ & $\ldots$ & $\ldots$ & $\ldots$ & $\ldots$ & 0.02 & $\ldots$ & $21.4,59.4$ \\
\hline & 1665 & 59.7 & 0.10 & $\ldots$ & $\ldots$ & 58.0 & 64.1 & 0.29 & 0.02 & New & $\ldots$ \\
\hline & 1667 & $\ldots$ & $\ldots$ & $\ldots$ & $\ldots$ & $\ldots$ & $\ldots$ & $\ldots$ & 0.02 & $\ldots$ & $\ldots$ \\
\hline $1922557+202854$ & 1612 & -5.3 & 3.68 & 12.9 & 3.15 & -8.7 & 14.6 & 14.88 & 0.01 & New & $\ldots$ \\
\hline & 1665 & -6.8 & 0.07 & 11.9 & 0.12 & -7.8 & 13.5 & 0.62 & 0.01 & New & $\ldots$ \\
\hline & 1667 & $\ldots$ & $\ldots$ & $\ldots$ & $\ldots$ & $\ldots$ & $\ldots$ & $\ldots$ & 0.01 & $\ldots$ & 7.1 \\
\hline $1930003+175601$ & 1612 & 23.6 & 0.13 & $\ldots$ & $\ldots$ & 20.8 & 25.3 & 0.33 & 0.02 & New & $\ldots$ \\
\hline & 1665 & $\ldots$ & $\ldots$ & $\ldots$ & $\ldots$ & $\ldots$ & $\ldots$ & $\ldots$ & 0.02 & $\ldots$ & 25.1 \\
\hline & 1667 & $\ldots$ & $\ldots$ & $\ldots$ & $\ldots$ & $\ldots$ & $\ldots$ & $\ldots$ & 0.02 & $\ldots$ & 25.7 \\
\hline IRAS $19312+1950$ & 1612 & 28.7 & 0.81 & $\ldots$ & $\ldots$ & 10.0 & 36.7 & 3.66 & 0.02 & 5 & $\ldots$ \\
\hline & 1665 & 32.8 & 0.10 & $\ldots$ & $\ldots$ & 29.5 & 42.7 & 0.71 & 0.02 & 5 & $\ldots$ \\
\hline & 1667 & 30.2 & 0.13 & $\ldots$ & $\ldots$ & 28.0 & 39.0 & 0.81 & 0.02 & 5 & $\ldots$ \\
\hline IRAS 19356+0754 & 1612 & -119.9 & 3.83 & $\ldots$ & $\ldots$ & -138.1 & -71.1 & 48.87 & 0.02 & New & $\ldots$ \\
\hline & 1665 & -94.7 & 0.87 & $\ldots$ & $\ldots$ & -134.8 & -74.3 & 11.67 & 0.02 & New & $\ldots$ \\
\hline & 1667 & -133.3 & 0.35 & $\ldots$ & $\ldots$ & -138.8 & -87.2 & 8.58 & 0.02 & New & $\ldots$ \\
\hline
\end{tabular}


Table 2

(Continued)

\begin{tabular}{|c|c|c|c|c|c|c|c|c|c|c|c|}
\hline Object & $\begin{array}{l}\text { Rest Freq. } \\
(\mathrm{MHz})\end{array}$ & $\begin{array}{c}V_{\mathrm{b}, \mathrm{p}}^{\mathrm{a}} \\
\left(\mathrm{km} \mathrm{s}^{-1}\right)\end{array}$ & $\begin{array}{c}F_{\mathrm{b}, \mathrm{p}}^{\mathrm{a}} \\
(\mathrm{Jy})\end{array}$ & $\begin{array}{c}V_{\mathrm{r}, \mathrm{p}}^{\mathrm{b}} \\
\left(\mathrm{km} \mathrm{s}^{-1}\right)\end{array}$ & $\begin{array}{l}F_{\mathrm{r}, \mathrm{p}}^{\mathrm{b}} \\
(\mathrm{Jy})\end{array}$ & $\begin{array}{c}V_{\mathrm{b}, \mathrm{e}} \mathrm{c} \\
\left(\mathrm{km} \mathrm{s}^{-1}\right)\end{array}$ & $\begin{array}{c}V_{\mathrm{r}, \mathrm{e}} \mathrm{c} \\
\left(\mathrm{km} \mathrm{s}^{-1}\right)\end{array}$ & $\begin{array}{c}I^{\mathrm{d}} \\
\left(\mathrm{Jy} \mathrm{km} \mathrm{s}^{-1}\right)\end{array}$ & $\begin{array}{l}\mathrm{rms} \\
(\mathrm{Jy})\end{array}$ & Ref. $^{\mathrm{e}}$ & $\begin{array}{c}\text { Absorptions }{ }^{\mathrm{f}} \\
\left(\mathrm{km} \mathrm{s}^{-1}\right)\end{array}$ \\
\hline \multirow[t]{2}{*}{$2015573+470534$} & 1612 & -9.3 & 5.15 & -0.8 & 2.61 & -13.2 & 7.2 & 24.05 & 0.01 & New & $\ldots$ \\
\hline & 1665 & -6.8 & 0.22 & -2.9 & 0.13 & -8.4 & -1.3 & 0.70 & 0.01 & New & $\ldots$ \\
\hline \multirow[t]{3}{*}{ IRAS $22097+5647$} & 1612 & $\ldots$ & $\ldots$ & $\ldots$ & $\ldots$ & $\ldots$ & $\ldots$ & $\ldots$ & 0.01 & .. & $\cdots$ \\
\hline & 1665 & 63.9 & 0.18 & -33.7 & 0.10 & -69.4 & -28.6 & 0.97 & 0.01 & New & $\ldots$ \\
\hline & 1667 & -65.3 & 0.64 & -43.9 & 0.14 & -66.4 & -34.0 & 1.87 & 0.01 & New & $\ldots$ \\
\hline & 1667 & $\ldots$ & $\ldots$ & $\ldots$ & $\ldots$ & $\ldots$ & $\ldots$ & $\ldots$ & 0.01 & $\ldots$ & $\ldots$ \\
\hline
\end{tabular}

Notes.

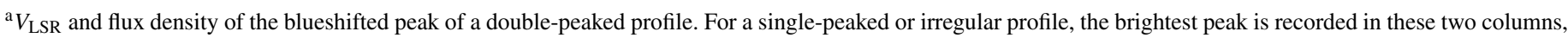
no matter whether it is really "blueshifted" or not.

b Same as the above footnote, but for the redshifted peak of a double-peaked profile, if it exists.

${ }^{\mathrm{c}} V_{\mathrm{LSR}}$ of the two ends of the whole emission profile. The cut-off is defined by the $3 \sigma$ flux level.

${ }^{\mathrm{d}}$ Integrated flux of the whole emission profile.

e References for known detections.

${ }^{\mathrm{f}} V_{\text {LSR }}$ of the absorption features, if any.

Refrences. (1) David et al. 1993; (2) te Lintel Hekkert 1991; (3) Engels \& Jimenez-Esteban 2007; (4) Sevenster et al. 2001 ; (5) Nakashima et al. 2011.

Table 3

Parameters of the $\mathrm{H}_{2} \mathrm{O}$ Maser Detections

\begin{tabular}{|c|c|c|c|c|c|c|c|c|c|}
\hline Object & $\begin{array}{c}V_{\mathrm{b}, \mathrm{p}^{\mathrm{a}}} \\
\left(\mathrm{km} \mathrm{s}^{-1}\right)\end{array}$ & $\begin{array}{l}F_{\mathrm{b}, \mathrm{p}}^{\mathrm{a}} \\
(\mathrm{Jy})\end{array}$ & $\begin{array}{c}V_{\mathrm{r}, \mathrm{p}}^{\mathrm{b}} \\
\left(\mathrm{km} \mathrm{s}^{-1}\right)\end{array}$ & $\begin{array}{l}F_{\mathrm{r}, \mathrm{p}}{ }^{\mathrm{b}} \\
(\mathrm{Jy})\end{array}$ & $\begin{array}{c}V_{\mathrm{b}, \mathrm{e}^{\mathrm{c}}} \\
\left(\mathrm{km} \mathrm{s}^{-1}\right)\end{array}$ & $\begin{array}{c}V_{\mathrm{r}, \mathrm{e}^{\mathrm{c}}} \\
\left(\mathrm{km} \mathrm{s}^{-1}\right)\end{array}$ & $\begin{array}{c}I^{\mathrm{d}} \\
\left(\mathrm{Jy} \mathrm{km} \mathrm{s}^{-1}\right)\end{array}$ & $\begin{array}{l}\mathrm{rms} \\
(\mathrm{Jy})\end{array}$ & Ref. $^{\mathrm{e}}$ \\
\hline IRAS $17055-0216$ & -46.7 & 0.49 & $\ldots$ & $\ldots$ & -47.5 & -45.9 & 0.47 & 0.04 & New \\
\hline IRAS 17132-0744 & 3.9 & 2.16 & $\ldots$ & $\ldots$ & -2.3 & 12.1 & 5.93 & 0.07 & 1 \\
\hline IRAS $17171-0843$ & -26.7 & 0.20 & -9.1 & 0.48 & -27.2 & -7.6 & 1.12 & 0.06 & 1 \\
\hline IRAS $17343+1052$ & -57.0 & 0.26 & $\ldots$ & $\ldots$ & -57.4 & -56.6 & 0.16 & 0.05 & 2 \\
\hline IRAS $18056-1514$ & 52.9 & 24.26 & $\ldots$ & $\ldots$ & 50.8 & 63.8 & 62.49 & 0.05 & 1 \\
\hline IRAS 18099-1449 & -1.6 & 0.19 & 8.6 & 0.16 & -2.9 & 11.1 & 0.76 & 0.04 & New \\
\hline IRAS $18100-1250$ & 79.8 & 1.25 & $\ldots$ & $\ldots$ & 78.2 & 80.7 & 1.34 & 0.06 & New \\
\hline IRAS $18117-1625$ & 68.5 & 0.15 & $\ldots$ & $\ldots$ & 67.7 & 69.1 & 0.16 & 0.04 & New \\
\hline IRAS $18127-1516$ & -15.4 & 4.53 & 13.2 & 0.20 & -17.7 & 14.0 & 9.57 & 0.06 & New \\
\hline IRAS 18286-0959 & 62.3 & 22.41 & $\ldots$ & $\ldots$ & -118.9 & 231.0 & 741.01 & 0.05 & 1 \\
\hline $\mathrm{OH} 16.3-3.0$ & 19.8 & 0.60 & 39.7 & 0.91 & 14.6 & 42.0 & 4.40 & 0.06 & 1 \\
\hline IRAS $18455+0448$ & 21.4 & 0.69 & 46.7 & 2.20 & 14.0 & 50.2 & 4.26 & 0.07 & 1 \\
\hline IRAS $18587+0521 B$ & -26.3 & 0.53 & 18.9 & 0.40 & -27.4 & 19.5 & 0.94 & 0.04 & New \\
\hline IRAS 19134+2131 & -41.1 & 0.42 & -12.3 & 2.27 & -42.0 & -8.4 & 5.63 & 0.06 & 3 \\
\hline $1919572+104808$ & 31.9 & 0.95 & 53.3 & 0.22 & 31.1 & 53.9 & 1.19 & 0.07 & 4 \\
\hline IRAS $19312+1950$ & 17.3 & 2.44 & $\ldots$ & $\ldots$ & 14.4 & 23.9 & 5.57 & 0.06 & 5 \\
\hline IRAS 19356+0754 & -35.3 & 0.19 & $\ldots$ & $\ldots$ & -144.7 & -26.2 & 0.45 & 0.01 & New \\
\hline IRAS 19464+3514 & 33.3 & 0.69 & $\cdots$ & $\cdots$ & 32.3 & 33.9 & 0.62 & 0.09 & 1 \\
\hline $1951461+272458$ & 32.3 & 0.48 & $\cdots$ & $\ldots$ & 29.4 & 32.7 & 0.54 & 0.07 & New \\
\hline IRAS $20021+2156$ & 20.2 & 0.22 & $\ldots$ & $\ldots$ & 19.1 & 21.0 & 0.27 & 0.04 & New \\
\hline IRAS $21522+6018$ & 20.4 & 0.32 & $\cdots$ & $\ldots$ & 19.8 & 21.0 & 0.23 & 0.04 & New \\
\hline IRAS $22097+5647$ & -49.2 & 54.99 & $\ldots$ & $\ldots$ & -60.9 & -39.3 & 81.84 & 0.08 & 1 \\
\hline IRAS 22394+6930 & -44.6 & 1.05 & $\cdots$ & $\ldots$ & -45.5 & -43.2 & 1.18 & 0.05 & New \\
\hline $2303421+614741$ & -8.4 & 0.51 & 2.3 & 0.19 & -9.1 & 2.9 & 0.73 & 0.04 & New \\
\hline
\end{tabular}

Notes.

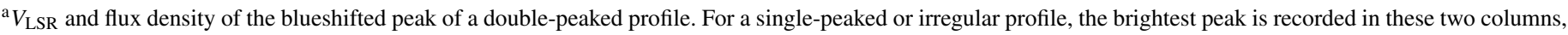
no matter whether it is really "blueshifted" or not.

b Same as the above footnote, but for the redshifted peak of a double-peaked profile, if it exists.

${ }^{\mathrm{c}} V_{\mathrm{LSR}}$ of the two ends of the whole emission profile. The cut-off is defined by the $3 \sigma$ flux level.

${ }^{\mathrm{d}}$ Integrated flux of the whole emission profile.

e References for known detections.

Refrences. (1) Paper I; (2) Benson \& Little-Marenin 1996; (3) Imai et al. 2007; (4) Engels \& Lewis 1996; (5) Nakashima et al. 2011.

IRAS 19356+0754, is not known because we are not able to find its $Q 2$ values due to insufficient photometric data. The red ellipse encloses a smaller number $(\sim 20)$ of objects which are isolated from the two main groups by having more negative $Q 1$ values (about -7 to -3 ). One of the WFs, $\mathrm{OH} 12.8-0.9$, sug- gested to be a late-AGB star (Boboltz \& Marvel 2005, 2007), and also the high-velocity object candidate, $1904448+042318$, are found in this group. The reason for their peculiar $Q 1$ values is not clear. The PNe are mainly found in the narrow region between the above three groups (i.e., with larger $Q 2$ values than 


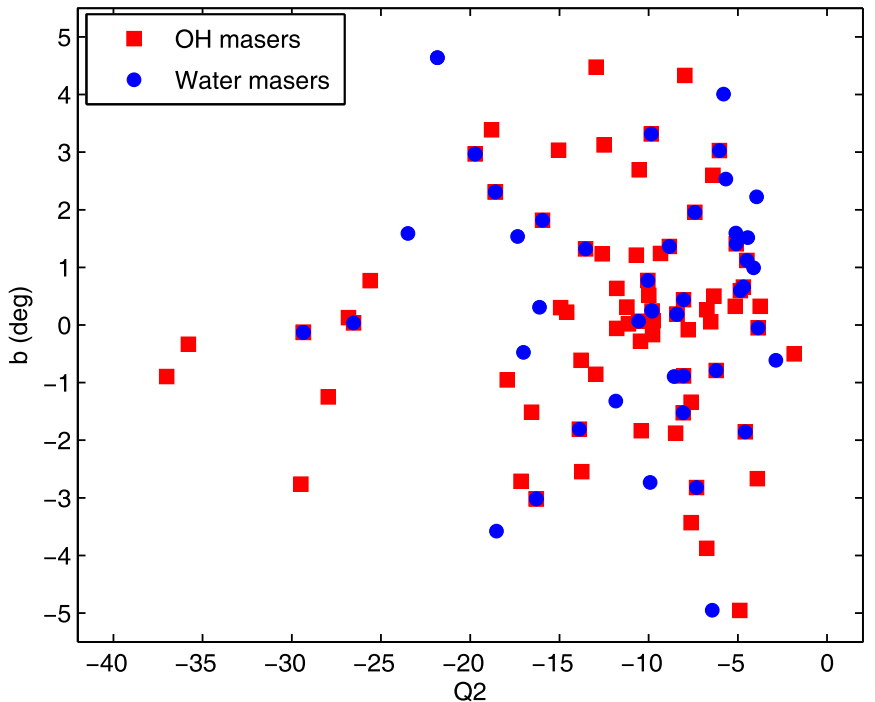

Figure 5. Galactic latitude, $b$, vs. $Q 2$ (see Equation (2)) of the $\mathrm{OH}$ and $\mathrm{H}_{2} \mathrm{O}$ sources detected in the current observation or Paper I.

(A color version of this figure is available in the online journal.)

Table 4

Parameters of the $\mathrm{OH}$ Maser Non-detections

\begin{tabular}{|c|c|c|c|}
\hline \multirow[t]{2}{*}{ Object } & \multicolumn{3}{|c|}{ rms (Jy) } \\
\hline & $1612 \mathrm{MHz}$ & $1665 \mathrm{MHz}$ & $1667 \mathrm{MHz}$ \\
\hline IRAS 16030-0634 & 0.03 & 0.05 & 0.03 \\
\hline IRAS $16131-0216$ & 0.02 & 0.02 & 0.02 \\
\hline IRAS $17055-0216$ & 0.02 & 0.02 & 0.02 \\
\hline IRAS $17132-0744$ & 0.25 & 0.02 & 0.02 \\
\hline IRAS $17193-0601$ & 0.03 & 0.02 & 0.02 \\
\hline $1750356-203743$ & 0.02 & 0.02 & 0.02 \\
\hline IRAS 18099-1449 & 0.02 & 0.02 & 0.02 \\
\hline IRAS $18100-1250$ & 0.01 & 0.01 & 0.01 \\
\hline IRAS 19085+1038 & 0.02 & 0.02 & 0.02 \\
\hline $1911358+133111$ & 0.02 & 0.01 & 0.01 \\
\hline $1912477+033435$ & 0.02 & 0.02 & 0.02 \\
\hline IRAS 19134+2131 & 0.01 & 0.01 & 0.01 \\
\hline $1918205+014659$ & 0.02 & 0.02 & 0.02 \\
\hline $1938574+103016$ & 0.02 & 0.02 & 0.02 \\
\hline $1951461+272458$ & 0.02 & 0.02 & 0.02 \\
\hline IRAS $20010+2508$ & 0.01 & 0.01 & 0.01 \\
\hline $2003357+284847$ & 0.02 & 0.02 & 0.02 \\
\hline $2003599+351617$ & 0.02 & 0.02 & 0.02 \\
\hline IRAS $20021+2156$ & 0.01 & 0.01 & 0.01 \\
\hline $2008383+410040$ & 0.01 & 0.01 & 0.01 \\
\hline IRAS $20215+6243$ & 0.01 & 0.01 & 0.01 \\
\hline IRAS $20305+6246$ & 0.02 & 0.02 & 0.02 \\
\hline $2040444+465322$ & 0.02 & 0.02 & 0.02 \\
\hline $2048044+390459$ & 0.02 & 0.02 & 0.02 \\
\hline $2048166+342724$ & 0.02 & 0.02 & 0.01 \\
\hline $2050135+594551$ & 0.02 & 0.02 & 0.02 \\
\hline IRAS $21509+6234$ & 0.01 & 0.01 & 0.01 \\
\hline IRAS $21522+6018$ & 0.02 & 0.02 & 0.02 \\
\hline IRAS $21563+5630$ & 0.01 & 0.01 & 0.01 \\
\hline
\end{tabular}

Note. The channel spacing of the spectrometer was between $0.5 \mathrm{~km} \mathrm{~s}^{-1}$ and $0.6 \mathrm{~km} \mathrm{~s}^{-1}$.

the PPNe), indicating a smaller mid-infrared flux than the PPNe. This is because the hot central star will become more exposed again in the PNe phase, and therefore a larger portion of the flux will be emitted from the star in the optical or near-infrared rather than from the mid-infrared. Finally, $Q 2$ could not be calculated
Table 5

Parameters of the $\mathrm{H}_{2} \mathrm{O}$ Maser Non-detections

\begin{tabular}{|c|c|}
\hline Object & $\begin{array}{l}\mathrm{rms} \\
(\mathrm{Jy})\end{array}$ \\
\hline $0038592+592746$ & 0.06 \\
\hline $0122182+634055$ & 0.06 \\
\hline $0128404+632737$ & 0.06 \\
\hline $0253373+691539$ & 0.06 \\
\hline $0358076+624425$ & 0.06 \\
\hline $0413220+501428$ & 0.07 \\
\hline $0433014+343840$ & 0.09 \\
\hline $0536468+314600$ & 0.08 \\
\hline $0540502+340241$ & 0.08 \\
\hline $0547450+003842$ & 0.09 \\
\hline $0608452+130841$ & 0.08 \\
\hline IRAS 16030-0634 & 0.07 \\
\hline IRAS $16131-0216$ & 0.06 \\
\hline IRAS 17193-0601 & 0.06 \\
\hline $1741385-241435$ & 0.10 \\
\hline $1750356-203743$ & 0.09 \\
\hline $1752536-184100$ & 0.08 \\
\hline $1807272-194639$ & 0.03 \\
\hline IRAS $18118-1615$ & 0.06 \\
\hline $1824037+063625$ & 0.07 \\
\hline $1824288-155108$ & 0.08 \\
\hline IRAS $18362-0521$ & 0.05 \\
\hline $1838595-052024$ & 0.07 \\
\hline $1848010+000448$ & 0.07 \\
\hline $1854158+011501$ & 0.07 \\
\hline $1854250+004958$ & 0.04 \\
\hline IRAS $18587+0521 \mathrm{~A}$ & 0.04 \\
\hline IRAS $18596+0605$ & 0.04 \\
\hline $1904448+042318$ & 0.07 \\
\hline IRAS 19027+0517 & 0.04 \\
\hline IRAS 19074+0534 & 0.05 \\
\hline IRAS $19085+1038$ & 0.04 \\
\hline $1911358+133111$ & 0.07 \\
\hline $1912477+033435$ & 0.09 \\
\hline $1914408+114449$ & 0.07 \\
\hline $1918205+014659$ & 0.10 \\
\hline $1922250+131851$ & 0.10 \\
\hline $1922557+202854$ & 0.04 \\
\hline $1923002+151051$ & 0.11 \\
\hline $1930003+175601$ & 0.04 \\
\hline $1938574+103016$ & 0.09 \\
\hline IRAS $20010+2508$ & 0.04 \\
\hline $2003357+284847$ & 0.09 \\
\hline $2003599+351617$ & 0.10 \\
\hline $2008383+410040$ & 0.09 \\
\hline $2009217+271859$ & 0.10 \\
\hline $2013142+370536$ & 0.09 \\
\hline $2015573+470534$ & 0.04 \\
\hline $2020151+364334$ & 0.04 \\
\hline IRAS $20215+6243$ & 0.04 \\
\hline $2029222+403543$ & 0.04 \\
\hline IRAS $20305+6246$ & 0.04 \\
\hline $2033464+450840$ & 0.08 \\
\hline $2040444+465322$ & 0.08 \\
\hline $2048044+390459$ & 0.09 \\
\hline $2048166+342724$ & 0.05 \\
\hline $2050135+594551$ & 0.05 \\
\hline $2053379+445807$ & 0.08 \\
\hline $2057130+482200$ & 0.08 \\
\hline $2100253+523017$ & 0.08 \\
\hline $2101550+495135$ & 0.04 \\
\hline $2117391+685509$ & 0.07 \\
\hline $2122090+492624$ & 0.04 \\
\hline IRAS $21509+6234$ & 0.04 \\
\hline $2155455+575106$ & 0.04 \\
\hline
\end{tabular}


Table 5

(Continued)

\begin{tabular}{ll}
\hline \hline Object & $\begin{array}{l}\mathrm{rms} \\
(\mathrm{Jy})\end{array}$ \\
\hline IRAS $21563+5630$ & 0.05 \\
$2158358+585722$ & 0.05 \\
$2204124+530401$ & 0.05 \\
$2219055+613616$ & 0.05 \\
$2219520+633532$ & 0.05 \\
$2233550+653918$ & 0.10 \\
IRAS 22394+5623 $251389+515042$ & 0.05 \\
$2259442+585956$ & 0.05 \\
$2312291+612534$ & 0.05 \\
$2317522+580511$ & 0.09 \\
$2335128+610005$ & 0.06 \\
2341559+641512 & 0.06 \\
2346058+632312 & 0.07 \\
IRAS 23489+6235 & 0.08 \\
IRAS 23554+5612 & 0.09 \\
IRAS 23561+6037 & 0.10 \\
\hline
\end{tabular}

Note. The channel spacing of the spectrometer was about $0.8 \mathrm{~km} \mathrm{~s}^{-1}$.

for two representative bipolar AGB stars, X Her and V Hya, because there are no data with respect to their $8 \mu \mathrm{m}$ flux. Their $Q 1$ values are -0.17 and 0.08 , respectively. From Figure 6, we can see that they are unlikely to be found in the region for spherical objects, no matter what their $Q 2$ values are. Instead, their $Q 1$ values $(\sim 0)$ are in the middle of the $Q 1$ range for "bipolar objects," which agrees with their bipolar nature.

Despite the small number of exceptional cases, we find a clear separation between the spherical and bipolar objects in the $Q 1-Q 2$ diagram. Most post-AGB stars and even some late AGB stars are aspherical, in particular many of them show a certain degree of bipolarity due to jets (see Section 1). The method used here by employing the $Q 1-Q 2$ diagram could isolate the clearly aspherical objects, which are likely (but not necessarily) objects at the late AGB/post-AGB phase.

\subsection{The Far-infrared AKARI Colors}

In Paper I, we have shown that the AGB and post-AGB stars occupy different regions in the AKARI [09]-[18] versus [18]-[65] two-color diagram, suggesting that the $A K A R I$ colors are useful for studying late-stage stellar evolution. Now we can extend this work by considering more known objects (Figure 7). The sample of PPNe and PNe is the same as that shown in Figure 6.

We find that the regionalization in Paper I is oversimplified because the objects are assumed to move along a single trend on the diagram as they evolve. However, the object distribution in Figure 7 suggests the presence of two major groups of sources. Here most of the PPNe are found mixing with some AGB maser sources (those assumed to have spherical envelopes) and WFs, in an elongated region (purple ellipse) almost parallel to the blackbody curve. The AGB stars appear at the higher temperature end, while the WFs are at the lower temperature end. This temperature tendency is similar to that in the $Q 1-Q 2$ diagram. However, here we have a stronger correlation between the PPNe and the blackbody curve. This is presumably due to the fact that the far-infrared colors are more sensitive to the temperature of the cold dust component, which contributes most of the flux from the SEDs of PPNe (e.g., IRAS 16342-3814; Murakawa \& Izumiura 2012). There are some objects, which deviate from the blackbody curve, that occupy the region with $0<[09]-[18]<2$ and $0<[18]-[65]<3$ (upper part of the green ellipse). However, there is no obvious sign on which kind of specific objects would behave like that. Nonetheless, we suspect that the aspherical objects will tend to move toward this region, because the high-velocity object

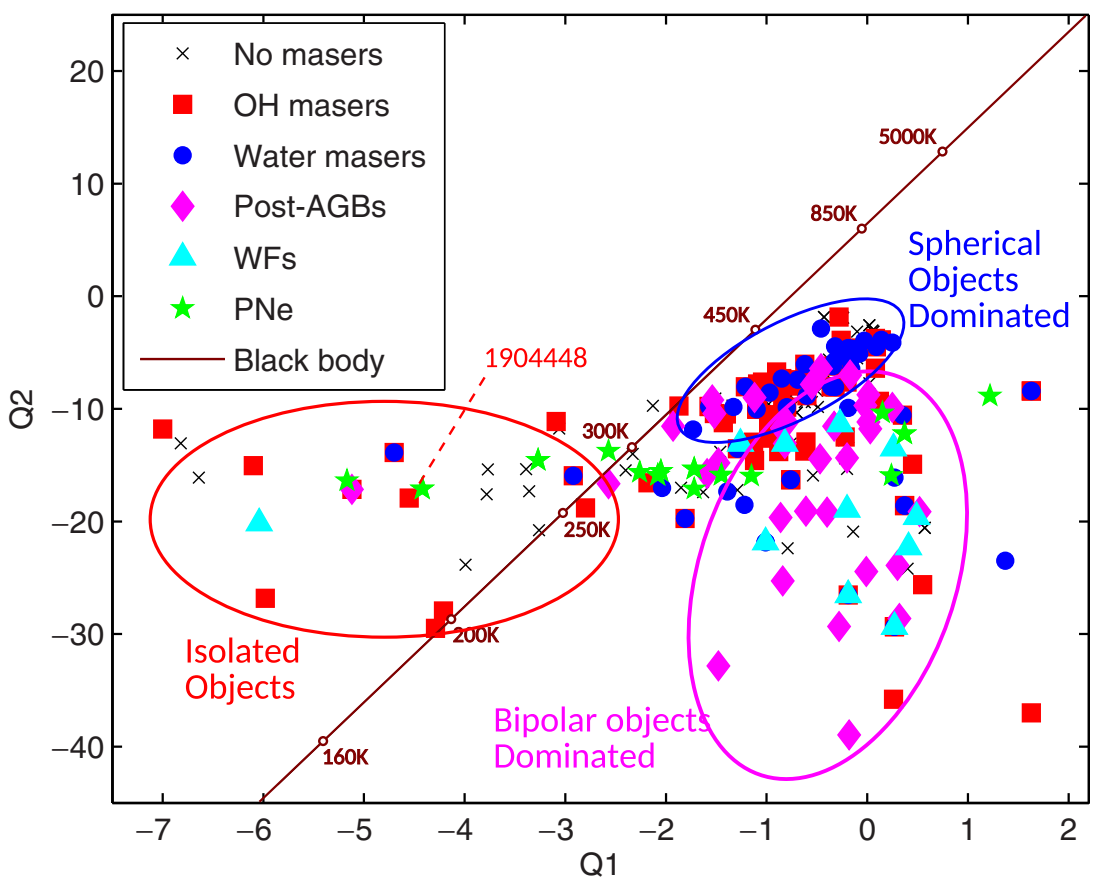

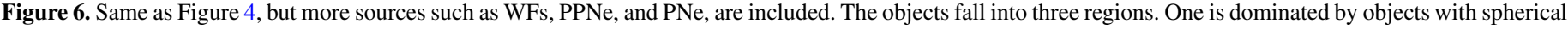

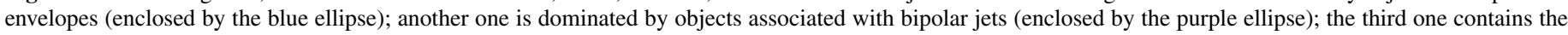
"isolated objects" (enclosed by the red ellipse). The reason for their peculiar $Q$ values is not clear (see Section 4.1 ). The blackbody curve is shown in brown.

(A color version of this figure is available in the online journal.) 


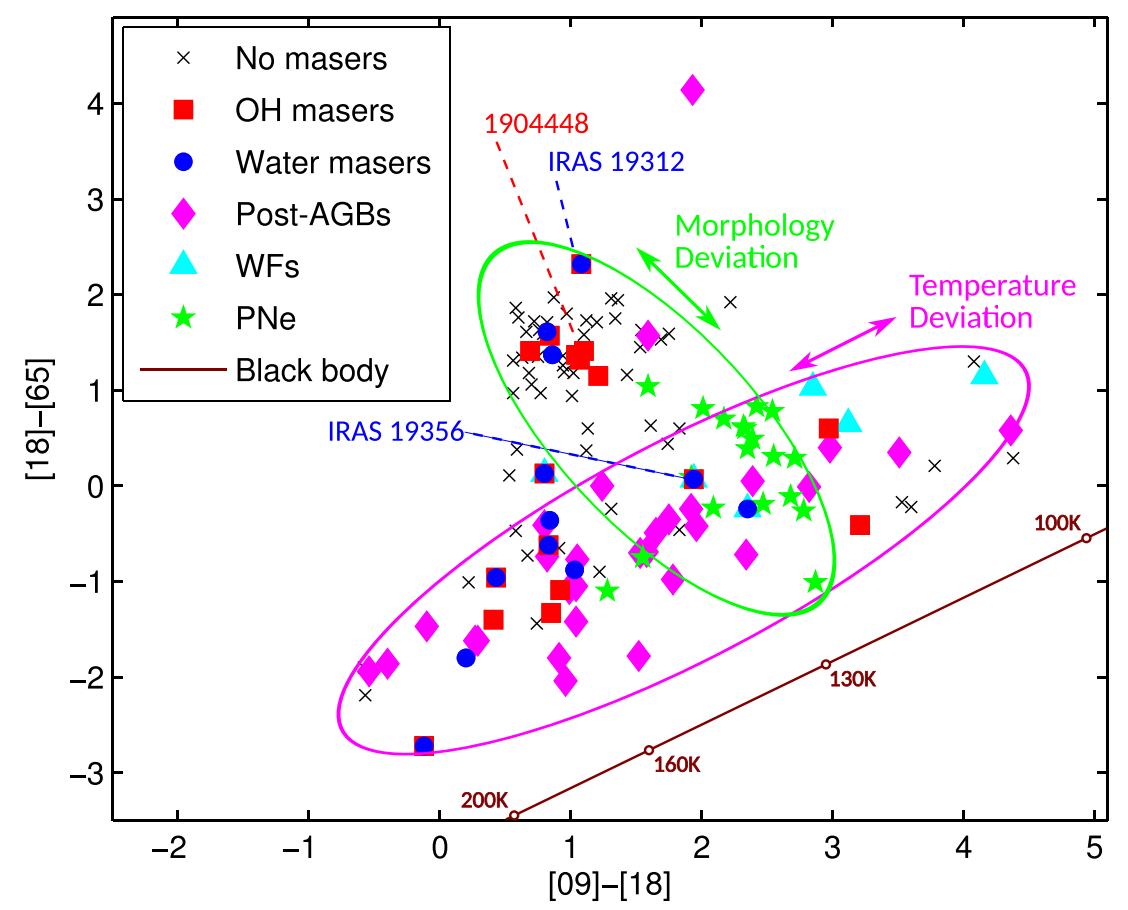

Figure 7. AKARI two-color diagram of the targets observed in the current project, the $\mathrm{H}_{2} \mathrm{O}$ sources in Paper I, and some other known sources (same sample as in Figure 6). The objects fall into two elongated regions. The region enclosed by the purple ellipse shows clear correlation with the blackbody temperature (shown in brown), while the one enclosed by the green ellipse seems to be related to the morphologies (e.g., spherical or bipolar).

(A color version of this figure is available in the online journal.)

candidate 1904448+042318, the known peculiar bipolar object IRAS 19312+1950 (Nakashima et al. 2011), and most of the selected $\mathrm{PNe}$ are found in this region.

Both the envelope morphology and temperature are common indicators to determine the evolutionary status of evolved stars. For instance, it is known that an AGB star usually has a spherical envelope, as opposed to the aspherical envelope of a post-AGB star, and the envelope temperature of the former is higher $(\geqslant 300 \mathrm{~K})$. However, Figure 7 seems to suggest that the change in temperature of the objects could be independent of their morphological change. That means, it is possible to have hotter AGB-like stars which are aspherical. In fact, as we mentioned before, W 43A, X Her and V Hya are examples of AGB stars with bipolar jets. If jets can be launched before the post-AGB phase, we suspect that WFs might not necessarily represent the short "young post-AGB" episode which has been widely accepted. By studying the SED, we found that half of the known WFs actually have characteristics of AGB stars (B. H. K. Yung et al. 2014, in preparation). Note that on the contrary, there are almost no spherical post-AGB stars (e.g., Lagadec et al. 2011). In short, the morphological change might not have a direct relationship to the evolutionary status: it could be safe to assume the cold post-AGB stars are aspherical, but it is not entirely correct to label all aspherical evolved stars as post-AGB stars, even though in most cases this is still true. Similar to the $Q 1-Q 2$ diagram, the $A K A R I$ two-color diagram could serve the purpose of identifying aspherical objects without assumptions on their evolutionary status, but the AKARI colors are more sensitive to the temperatures of the colder envelopes that mainly shine at far-infrared wavelengths.

\section{SUMMARY AND CONCLUSION}

We have conducted an $\mathrm{OH}$ and $\mathrm{H}_{2} \mathrm{O}$ maser survey with targets selected by the far-infrared AKARI colors. We found a new WF candidate, IRAS $19356+0754$, and a few possible high-velocity $\mathrm{OH}$ objects. New $\mathrm{H}_{2} \mathrm{O}$ maser components were detected for the known WF, IRAS 18286-0959, which might be a hint on jet acceleration. We then studied the maser sources, and other known objects such as PPNe and PNe, using the $Q 1$ and $Q 2$ parameters as well as the AKARI colors. While the $Q 1-Q 2$ diagram seems to be effective in separating the spherical and bipolar objects in general, the AKARI colors show further that the morphological change in cold sources is not necessarily related to their evolutionary status, i.e., even though many of the aspherical objects are found to be post-AGB stars, some AGB stars may also develop jets before reaching the post-AGB phase. We suggest that the efficiency of identifying oxygenrich objects during the late stages of stellar evolution (i.e., late AGB/post-AGB stars) could be improved by considering together the maser properties, the $Q$-parameters, and the $A K A R I$ colors.

We thank the anonymous referee for the comments and suggestions. This work is supported by a grant awarded to J.N. from the Research Grants Council of Hong Kong (project code: HKU 704411P) and the Small Project Funding of the University of Hong Kong (project code: 201007176004). The results are based on observations with the $100 \mathrm{~m}$ telescope of the MPIfR (Max-Planck-Institut für Radioastronomie) at Effelsberg; AKARI, a JAXA project with the participation of ESA; Two Micron All Sky Survey, which is a joint project of the University of Massachusetts and the Infrared Processing and Analysis Center/California Institute of Technology, funded by the National Aeronautics and Space Administration and the National Science Foundation; and Midcourse Space Experiment. Processing of the data was funded by the Ballistic Missile Defense Organization with additional support from NASA Office of Space Science. This research has also made use of the 
NASA/IPAC Infrared Science Archive, which is operated by the Jet Propulsion Laboratory, California Institute of Technology, under contract with the National Aeronautics and Space Administration.

\section{REFERENCES}

Benjamin, R. A., Churchwell, E., Babler, B. L., et al. 2003, PASP, 115, 953

Benson, P. J., \& Little-Marenin, I. R. 1996, ApJS, 106, 579

Blöcker, T. 1995, A\&A, 299, 755

Boboltz, D. A., \& Marvel, K. B. 2005, ApJL, 627, L45

Boboltz, D. A., \& Marvel, K. B. 2007, ApJ, 665, 680

Churchwell, E., Babler, B. L., Meade, M. R., et al. 2009, PASP, 121, 213

David, P., Le Squeren, A. M., Sivagnanam, P., \& Braz, M. A. 1993, A\&AS, 98, 245

Deacon, R. M., Chapman, J. M., \& Green, A. J. 2004, ApJS, 155, 595

Deacon, R. M., Chapman, J. M., \& Green, A. J. 2007, ApJ, 658, 1096

Deguchi, S., Nakashima, J., Kwok, S., \& Koning, N. 2007, ApJ, 664, 1130

Desmurs, J.-F. 2012, in IAU Symp. 287, Cosmic Masers-from $\mathrm{OH}$ to $\mathrm{H}_{0}$, ed. R. S. Booth, E. M. L. Humphries, \& W. H. T. Vlemmings (Cambridge: Cambridge Univ. Press), 217

Egan, M. P., Mizuno, D. R., Engelke, C. W., et al. 2003, The Midcourse Space Experiment Point Source Catalog Version 2.3 Explanatory Guide (Washington, DC: Storming Media)

Engels, D., \& Jimenez-Esteban, F. 2007, A\&A, 475, 941

Engels, D., \& Lewis, B. M. 1996, A\&AS, 116, 117

Engels, D., Schmid-Burgk, J., \& Walmsley, C. M. 1986, A\&A, 167, 129

Fok, T. K. T., Nakashima, J.-i., Yung, B. H. K., Hsia, C.-H., \& Deguchi, S. 2012, ApJ, 760, 65

Frank, A., \& Blackman, E. G. 2004, ApJ, 614, 737

Habing, H. J. 1996, A\&ARv, 7, 97

Hirano, N., Shinnaga, H., \& Dinh-V-Trung, et al. 2004, ApJL, 616, L43

Huggins, P. J. 2007, ApJ, 663, 342

Imai, H. 2007, in IAU Symp. 242, Astrophysical Masers and Their Environments, ed. W. Baan \& J. Chapman (Cambridge: Cambridge Univ. Press), 279

Imai, H., Obara, K., Diamond, P. J., Omodaka, T., \& Sasao, T. 2002, Natur, 417,829

Imai, H., Sahai, R., \& Morris, M. 2007, ApJ, 669, 424

Kataza, H., Alfageme, C., Cassatella, A., et al. 2010, AKARI-FIS Bright Source Catalogue Release Note Version 1.0 (Sagamihara: ISAS)

Kothes, R., \& Dougherty, S. M. 2007, A\&A, 468, 993
Lagadec, E., Verhoelst, T., Mékarnia, D., et al. 2011, MNRAS, 417, 32

Lovas, F. J. 2004, JPCRD, 33, 177

Meixner, M., Ueta, T., Dayal, A., et al. 1999, ApJS, 122, 221

Messineo, M., Menten, K. M., Churchwell, E., \& Habing, H. 2012, A\&A, 537, A10

Morita, K.-I., Hasegawa, T., Ukita, N., Okumura, S. K., \& Ishiguro, M. 1992, PASJ, 44, 373

Murakawa, K., \& Izumiura, H. 2012, A\&A, 544, A58

Nakashima, J. 2005, ApJ, 620, 943

Nakashima, J., Deguchi, S., Imai, H., Kemball, A., \& Lewis, B. M. 2011, ApJ, 728,76

Negueruela, I., González-Fernández, C., Marco, A., \& Clark, J. S. 2011, A\&A, 528, A59

Negueruela, I., \& Schurch, M. P. E. 2007, A\&A, 461, 631

Nordhaus, J., \& Blackman, E. G. 2006, MNRAS, 370, 2004

Ott, M., Witzel, A., Quirrenbach, A., et al. 1994, A\&A, 284, 331

Pérez-Sánchez, A. F., Vlemmings, W. H. T., \& Chapman, J. M. 2011, MNRAS, 418, 1402

Ruffle, P. M. E., Zijlstra, A. A., Walsh, J. R., et al. 2004, MNRAS, 353, 796

Sahai, R., \& Trauger, J. T. 1998, AJ, 116, 1357

Sevenster, M. N., van Langevelde, H. J., Moody, R. A., et al. 2001, A\&A, 366, 481

Skrutskie, M. F., Cutri, R. M., Stiening, R., et al. 2006, AJ, 131, 1163

Suárez, O., Gómez, J. F., \& Miranda, L. F. 2008, ApJ, 689, 430

Suárez, O., Gómez, J. F., \& Morata, O. 2007, A\&A, 467, 1085

Takaba, H., Ukita, N., Miyaji, T., \& Miyoshi, M. 1994, PASJ, 46, 629

te Lintel Hekkert, P. 1991, A\&AS, 90, 327

te Lintel Hekkert, P., \& Chapman, J. M. 1996, A\&AS, 119, 459

te Lintel Hekkert, P., Versteege-Hansel, H. A., Habing, H. J., \& Wiertz, M. 1989, A\&AS, 78, 399

Valdettaro, R., Palla, F., Brand, J., et al. 2001, A\&A, 368, 845

van der Veen, W. E. C. J., \& Habing, H. J. 1988, A\&A, 194, 125

Van Winckel, H. 2003, ARA\&A, 41, 391

Walsh, A. J., Breen, S. L., Bains, I., \& Vlemmings, W. H. T. 2009, MNRAS, 394, L70

Wright, E. L., Eisenhardt, P. R. M., Mainzer, A. K., et al. 2010, AJ, 140,1868

Yamamura, I., Makiuti, S., Ikeda, N., et al. 2010, AKARI-FIS Bright Source Catalogue Release Note Version 1.0 (Sagamihara: ISAS)

Yung, B. H. K., Nakashima, J., Imai, H., et al. 2011, ApJ, 741, 94

Yung, B. H. K., Nakashima, J., Imai, H., et al. 2013, ApJ, 769, 20

Zijlstra, A. A., Chapman, J. M., te Lintel Hekkert, P., et al. 2001, MNRAS, 322,280 